\title{
Divergent transcriptomic responses underlying the ranaviruses-amphibian interaction processes on interspecies infection of Chinese giant salamander
}

\author{
Fei Ke, Jian-Fang Gui, Zhong-Yuan Chen, Tao Li, Cun-Ke Lei, Zi-Hao Wang and Qi-Ya Zhang*
}

\begin{abstract}
Background: Ranaviruses (family Iridoviridae, nucleocytoplasmic large DNA viruses) have been reported as promiscuous pathogens of cold-blooded vertebrates. Rana grylio virus (RGV, a ranavirus), from diseased frog Rana grylio with a genome of $105.79 \mathrm{~kb}$ and Andrias davidianus ranavirus (ADRV), from diseased Chinese giant salamander (CGS) with a genome of $106.73 \mathrm{~kb}$, contains 99\% homologous genes.

Results: To uncover the differences in virus replication and host responses under interspecies infection, we analyzed transcriptomes of CGS challenged with RGV and ADRV in different time points $(1 \mathrm{~d}, 7 \mathrm{~d})$ for the first time. A total of 128,533 unigenes were obtained from 820,858,128 clean reads. Transcriptome analysis revealed stronger gene expression of RGV than ADRV at $1 \mathrm{~d}$ post infection (dpi), which was supported by infection in vitro. RGV replicated faster and had higher titers than ADRV in cultured CGS cell line. RT-qPCR revealed the RGV genes including the immediate early gene $(R G V-89 R)$ had higher expression level than that of ADRV at $1 \mathrm{dpi}$. It further verified the acute infection of RGV in interspecies infection.

The number of differentially expressed genes and enriched pathways from RGV were lower than that from ADRV, which reflected the variant host responses at transcriptional level. No obvious changes of key components in pathway "Antigen processing and presentation" were detected for RGV at $1 \mathrm{dpi}$. Contrarily, ADRV infection downregulated the expression levels of $\mathrm{MHC}$ I and CD8. The divergent host immune responses revealed the differences between interspecies and natural infection, which may resulted in different fates of the two viruses. Altogether, these results revealed the differences in transcriptome responses among ranavirus interspecies infection of amphibian and new insights in DNA virus-host interactions in interspecies infection.
\end{abstract}

Conclusion: The DNA virus (RGV) not only expressed self-genes and replicated quickly after entry into host under interspecies infection, but also avoided the over-activation of host responses. The strategy could gain time for the survival of interspecies pathogen, and may provide opportunity for its adaptive evolution and interspecies transmission.

Keywords: Interspecies infection, Ranavirus, Amphibian, Transcriptome response, Chinese giant salamander, Virus-host interactions, Immune pathway

* Correspondence: zhangqy@ihb.ac.cn

State Key Laboratory of Freshwater Ecology and Biotechnology, Institute of

Hydrobiology, Chinese Academy of Sciences, Wuhan 430072, China 


\section{Background}

Several emerging and threatening viruses are concerned with interspecies infection between human beings and lower vertebrates or invertebrates, such as Influenza A virus, Zika virus, Ebola virus, and so on. Most of them are RNA virus [1-3]. Numerous advances on interspecies infection that several species were infected by the same virus have been gained until now [4-7]. Besides this, several viruses in lower vertebrates and invertebrates also had a wide range of hosts, such as viruses in the family Iridoviridae, Nodaviridae, and Rhabdoviridae $[8,9]$. Wide host range increased the threat caused by the virus and the possibility of interspecies infection.

Aquaculture has become one of the fastest and most efficient agricultural production industries in the world over the last three decades [10]. However, viral diseases have hampered its development [11, 12]. As a genus of the family Iridoviridae, viruses in Ranavirus have icosahedral capsids and double-stranded, nucleocytoplasmic large DNA genomes [13, 14]. These viruses have been reported as promiscuous pathogens of cold-blooded vertebrates [15] and have been isolated from different aquaculture animals including fish [16-18], amphibians [19-21], and reptiles [22, 23]. Currently ranaviruses constitute the majority of iridoviruses [13]. Many of them are highly pathogenic and represent great threat to cultured and wild lower vertebrates [18]. Sequence determination and bioinformatic analysis reveal several recent host shifts among ranaviruses [24, 25]. It has been reported that frog virus 3 (FV3, a ranavirus) or FV3-like ranavirus could infect heterologous species [26, 27].

Our lab has focused on ranaviruses for a long time, including virus isolation, genome sequencing, functional gene identification, and so on [28-35]. Among them, two ranaviruses were isolated. One is Rana grylio virus (RGV) which was isolated from diseased pig frog Rana grylio (Anura amphibian) [36]. The other is Andrias davidianus ranavirus (ADRV) which was isolated from diseased Chinese giant salamander Andrias davidianus (CGS hereafter, urodele amphibian) [32]. Complete sequences of the two ranaviruses have been determined $[31,32]$. The genome size of RGV is $105.79 \mathrm{~kb}$ in length with 106 predicted genes, and the ADRV genome is $106.73 \mathrm{~kb}$ in size with 101 predicted genes. RGV and ADRV had a close relationship by phylogenetic analysis. Moreover, their genomes have high colinearity based on sequence comparisons. ADRV contains 99\% homologous genes with RGV [32].

The CGS is the largest extant amphibian species and known as a living fossil from 350 million years ago [37]. Although the wild population has been considered as endangered species, it has been farmed in China for scientific conservation and economic use. The two viruses (RGV and ADRV) infection in their natural host both caused systemic hemorrhage and intracellular virus particles with crystalline aggregation (Fig. 1). RGV can replicate and cause cytopathic effects in cultured CGS thymus cell (GSTC) line which was the first established cell line of CGS $[38,39]$. The two viruses with high similarity provided us useful materials to investigate the interspecies infection of ranaviruses. On the basis of the above, RGV, a non-natural pathogen, was used to infect CGS as interspecies infection in this study. Simultaneously, ADRV, a natural pathogen, was also used to infect CGS. Their replication and the host responses were then analyzed with 15 transcriptome libraries.

\section{Results}

Differences in expression of virus genes between interspecies and natural infection

A total of $820,858,128$ cleaned reads were obtained from 15 transcriptome libraries (more than 150 million reads per sample) covering RGV-1d, RGV-7d, ADRV-1d and ADRV$7 d$ groups. The data quality evaluation with more than $94 \%$ in Q30 of each sample proved its high quality. The detailed number of cleaned reads was shown in Table 1.

A portion of the cleaned reads were successfully mapped to the RGV (NCBI accession number: JQ654586) and ADRV (KC865735) genome. The number of the cleaned reads mapped to virus genome ranged from 460 to 53,720 . Of them, the paired reads located in open reading frames (covered virus gene) were selected for evaluating the relative gene expression. The average number of paired reads covering virus gene was 663 for RGV-1d and 16 for ADRV-1d, while the number was 8 for RGV-7d and 10,254 for ADRV-7d (Fig. 2a). On the whole, viral reads were detected in all virus-treated groups. But the number of reads from RGV was less than that from ADRV. The number of reads from RGV1d was more than that from RGV-7d and ADRV-1d, while the number of reads from ADRV-1d was less than that from ADRV-7d. 95 genes of RGV (106 predicted genes in all) and 29 genes of ADRV (101 predicted genes in all) had corresponding paired reads at $1 \mathrm{dpi}$, while 16 genes of RGV and 93 genes of ADRV were counted in samples at $7 \mathrm{dpi}$ (Table 1). Most of the viral genes had corresponding paired reads in the libraries except 10 genes for RGV and 8 genes for ADRV. Detailed information of the paired reads was collected in Additional file 1: Table S1 and S2. The FPKM values of virus genes were also calculated based on the paired reads. The results showed a similar tendency as revealed by comparison of the number of paired reads.

\section{Diversity of host genes between interspecies and natural infection}

128,533 unigenes covering the 15 libraries were obtained by de novo assembly (Table 1 ). The number of unigenes 

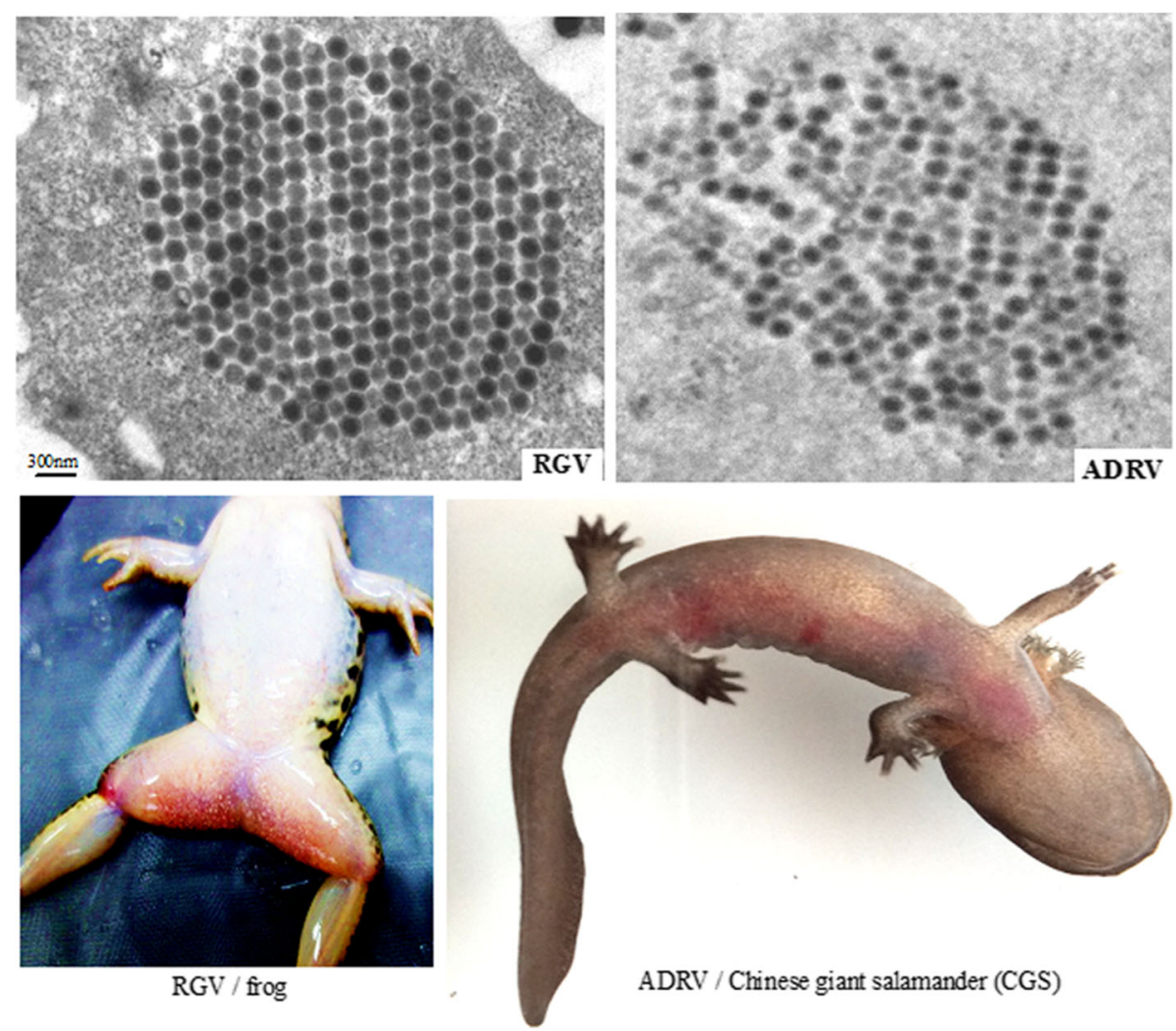

Fig. 1 Morphology and infection of RGV and ADRV. The ultrastructure of the viruses (RGV, ADRV). And the diseased animals were infected by their respective natural pathogen (RGV/frog, ADRV/Chinese giant salamander (CGS))

was 92,642, 97,513, 92,198, 87,131, and 95,375 for Control, RGV-1d, RGV-7d, ADRV-1d, and ADRV-7d, respectively. The N50 and average length of unigenes were 1567 and 881 bp respectively. Sequence length distribution of the unigenes was shown in Additional file 2: Figure S1.

A total of 2162 DEGs (1222 up-regulated and 940 down-regulated) in RGV treatments and 4265 DEGs (2928 up-regulated and 1337 down-regulated) in ADRV treatments were identified when compared with control. Among them, 557 DEGs (501 up-regulated) were identified in RGV-1d, meanwhile 1013 DEGs (763 upregulated) were found in ADRV-1d. They shared 391 up-regulated and 22 down-regulated DEGs. RGV-7d possessed 1852 DEGs (933 up-regulated), while ADRV7d possessed 3880 DEGs (2694 up-regulated), with 466 up and 261 down DEGs in common (Fig. 2b).

Eight of the top 10 up-regulated DEGs were found identical between RGV-1d and ADRV-1d, such as homologues of proteasome subunit beta type-8, serine protease, heat shock $70 \mathrm{kDa}$ protein, and ATPbinding cassette sub-famlily B. Only 2 common DEGs (unknown function) were found in the top 10 downregulated DEGs between the two groups (Additional file 3: Table S3). For the top 10 DEGs between RGV-7d and ADRV-7d, 3 up- and 2 downregulated DEGs were identified as common DEGs respectively (Additional file 3: Table S4).

\section{RGV replicated faster than ADRV in vitro}

The replication and the process of cytopathic effect (CPE) were examined in cultured GSTC cells. Both the two viruses replicated successfully in the cells (Fig. 3a). The obvious CPE caused by RGV appeared at $36 \mathrm{~h}$ post infection (hpi), while the CPE induced by ADRV was obvious at $60 \mathrm{hpi}$. The one-step growth curves of the two viruses was then determined. Results showed that the titer of RGV was significantly more than that of ADRV at 1 day post infection. After 4 days post infection, the growth curves of the two viruses both showed a nearly horizontal level, but the maximal titer of $\operatorname{RGV}\left(10^{6.9} \mathrm{TCID}_{50} / \mathrm{mL}\right)$ was more than that of $\operatorname{ADRV}\left(10^{6.1} \mathrm{TCID}_{50} / \mathrm{mL}\right)$ (Fig. 3b). The ultrastructural observation showed the intracellular virus particles with crystalline aggregation in GSTC cells for the two viruses (Fig. 3c). These results revealed that the growth of RGV was faster than ADRV. 
Table 1 Summary of the sequence data of CGS transcriptome, number of virus gene with paired reads, and significantly enriched immune pathways from different treatments

\begin{tabular}{|c|c|c|c|c|c|c|c|c|c|c|c|c|}
\hline \multicolumn{2}{|c|}{ Sample treatment } & \multicolumn{3}{|l|}{ CGS } & \multirow{2}{*}{$\begin{array}{l}\text { Number of virus } \\
\text { genes with paired } \\
\text { reads }\end{array}$} & \multicolumn{7}{|c|}{ Significantly enriched immune pathways } \\
\hline & & $\begin{array}{l}\text { Number of } \\
\text { cleaned reads }\end{array}$ & $\begin{array}{l}\text { Number of } \\
\text { Unigenes }\end{array}$ & $\begin{array}{l}\text { Number of DEGs } \\
\text { (compared to Control) }\end{array}$ & & $\overline{\mathrm{HCL}}$ & TLR & $\mathrm{CCC}$ & APP & NKC & III & $\mathrm{RIG}$ \\
\hline 1 & Control & $51,382,240$ & 70,307 & & & & & & & & & \\
\hline 2 & Control & $56,930,824$ & 74,222 & & & & & & & & & \\
\hline 3 & Control & $48,322,278$ & 72,107 & & & & & & & & & \\
\hline & Control-total & $156,635,342$ & 92,642 & & & & & & & & & \\
\hline 4 & RGV-1d & $54,425,646$ & 72,588 & $557(501 \uparrow, 56 \downarrow)$ & 95 & + & + & & & & & \\
\hline 5 & RGV-1d & $58,594,944$ & 75,232 & & & & & & & & & \\
\hline 6 & RGV-1d & $63,939,152$ & 76,704 & & & & & & & & & \\
\hline & RGV-1d-total & $176,959,742$ & 97,513 & & & & & & & & & \\
\hline 7 & RGV-7d & $49,123,866$ & 67,404 & $1852(933 \uparrow, 919 \downarrow)$ & 16 & + & & & + & + & & \\
\hline 8 & RGV-7d & $52,736,612$ & 73,301 & & & & & & & & & \\
\hline 9 & RGV-7d & $50,018,476$ & 70,402 & & & & & & & & & \\
\hline & RGV-7d-total & $151,878,954$ & 92,198 & & & & & & & & & \\
\hline 10 & ADRV-1d & $56,001,870$ & 68,499 & $1013(763 \uparrow, 250 \downarrow)$ & 29 & + & + & + & + & & & \\
\hline 11 & ADRV-1d & $47,824,738$ & 67,468 & & & & & & & & & \\
\hline 12 & ADRV-1d & $66,289,046$ & 69,480 & & & & & & & & & \\
\hline & ADRV-1d-total & $170,115,654$ & 87,131 & & & & & & & & & \\
\hline 13 & ADRV-7d & $59,093,102$ & 67,797 & $3880(2694 \uparrow, 1186 \downarrow)$ & 93 & + & + & + & & + & + & + \\
\hline 14 & ADRV-7d & $56,800,712$ & 77,340 & & & & & & & & & \\
\hline 15 & ADRV-7d & $49,374,622$ & 73,957 & & & & & & & & & \\
\hline & ADRV-7d-total & $165,268,436$ & 95,375 & & & & & & & & & \\
\hline & Total & $820,858,128$ & 128,533 & & & & & & & & & \\
\hline
\end{tabular}

HCL hematopoietic cell lineage, TLR toll-like receptor signaling pathway, CCC complement and coagulation cascades, APP antigen processing and presentation, NKC natural killer cell mediated cytotoxicity, III intestinal immune network for IgA production, RIG rIG-I-like receptor signaling pathway

" $\uparrow$ " and " $\downarrow$ " indicates up- and down-regulate respectively. " + " means significantly enriched

Host responses between interspecies and natural infection DEGs obtained from groups at 1 day post injection (dpi) were significantly enriched into 58 (RGV) and 85 (ADRV) Go (Gene Ontology) terms respectively. In the top 30 Go terms, both comparisons showed relatively similar responses including "response to stimulus" and "regulation of cellular process" (Fig. 4). There were some distinct top Go terms for the two comparisons. For example, the Go term "Immune system process" was significantly enriched in RGV-1d, while the ADRV-1d contained top Go terms related to cell death including "Regulation of cell death", "Regulation of apoptotic process", and "Regulation of programmed cell death". DEGs from groups at $7 \mathrm{dpi}$ were significantly enriched into 26 (RGV) and 435 (ADRV) Go terms. There were relatively large differences in the top enriched Go terms between RGV-7d and ADRV-7d (Fig. 4). Significantly enriched Go terms focused on biological, cellular, and metabolic process and immune response in RGV-7d. Notably, the Go term "Antigen processing and presentation of peptide antigen via MHC I" was largely enriched in RGV-7d. However, Go terms related to cellular events including "cell migration" and "cell differentiation" were significantly enriched in ADRV-7d besides the Go terms related to stimulus and immune response. These results revealed the differences in host transcriptome responses to two kinds of viruses.

For the top 30 Go terms between RGV infected groups at $1 \mathrm{dpi}$ and $7 \mathrm{dpi}, \mathrm{RGV}-7 \mathrm{~d}$ showed more enriched Go terms in antigen processing and presentation, as well as oxidation reduction in the category of biological process. Most of the top 30 Go terms were different between ADRV-1d and ADRV-7d. Detailed information of all the enriched Go terms was collected in Additional file 4: Table S5-S8.

In addition, the results showed that the enrichment ratio had a wide range across different comparisons. The differences among the enrichment ratio were resulted from the differences in sample number, which is the number of enriched DEGs of the Go term. Because the number of DEGs was divergent among the four groups, the scores were different across different comparisons, 

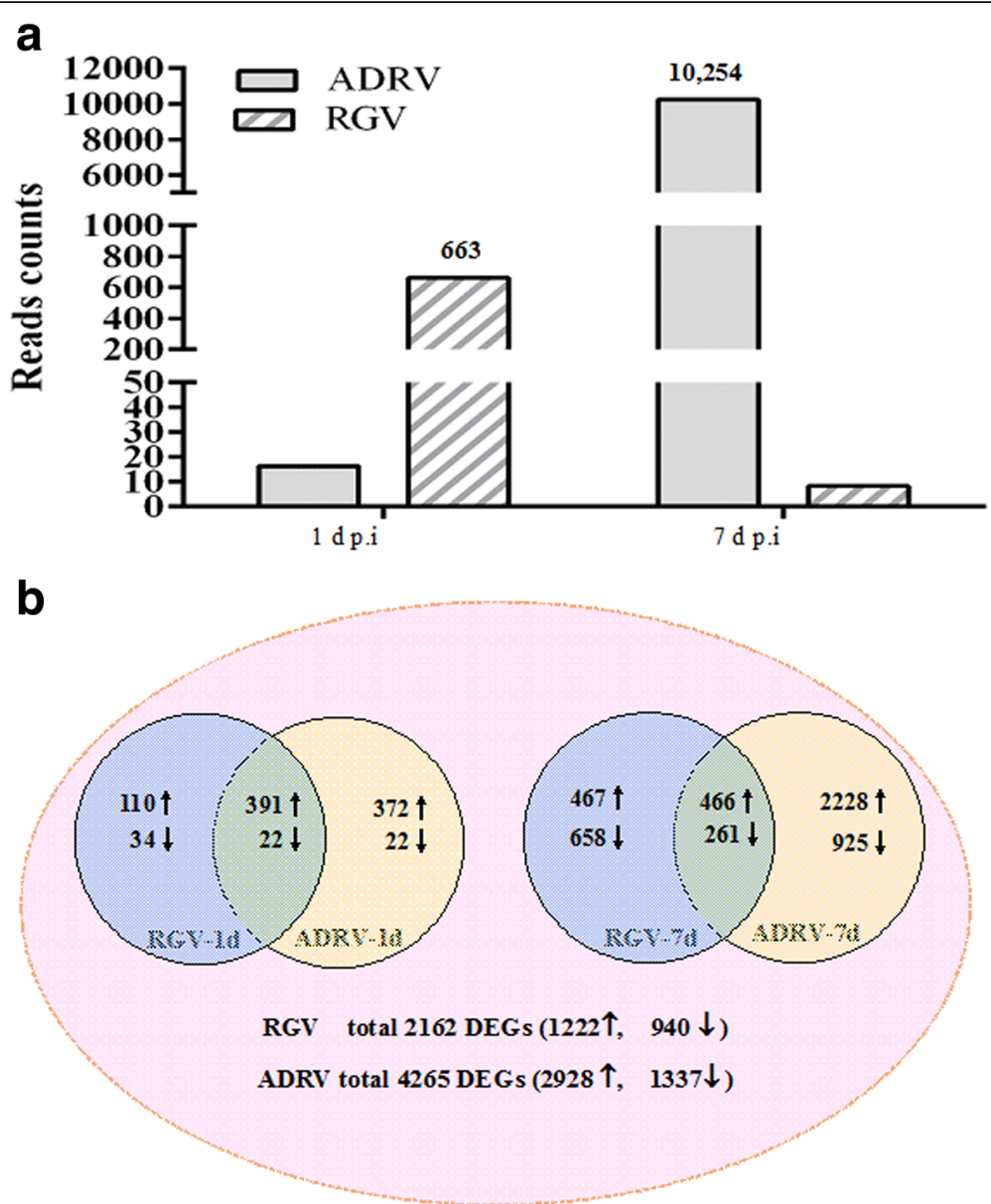

Fig. 2 Expression of virus genes and number of DEGs (compared with control) in CGS. a number of paired reads covering genes of ADRV and RGV counted by featureCounts software. The Y-axes means the number of paired reads related to the genes. $\mathbf{b}$ Venn diagram of DEGs at 1 dpi or $7 \mathrm{dpi}$. Each circle represents a comparison that indicated in the cycle. Up- and down-regulated DEGs are indicated by " $\uparrow$ " and " $\downarrow$ ", respectively. Overlap region of two cycles represents DEGs in common

which reflected the divergent transcriptome responses under different conditions.

DEGs of RGV-1d, RGV-7d, ADRV-1d, and ADRV-7d were significantly enriched into $13,8,15$, and 20 KEGG (Kyoto Encyclopedia of Genes and Genomes) pathways respectively (Table 2). 10 of the significantly enriched pathways including "cytokine-cytokine receptor interaction", "malaria", "hematopoietic cell lineage", "transcriptional misregulation in cancer", "Jak-STAT signaling pathway", "TNF signaling pathway", "rheumatoid arthritis", "AGE-RAGE signaling pathway in diabetic complications", "toll-like receptor signaling pathway", and "legionellosis" were identical between RGV and ADRV infected groups at $1 \mathrm{dpi}$. However, RGV-1d contained the enriched pathway "NF-kappa B signaling pathway" and ADRV-1d had the enriched pathway "Antigen processing and presentation" and "Complement and coagulation cascades". The pathways "cytokine-cytokine receptor interaction", "hematopoietic cell lineage", "natural killer cell mediated cytotoxicity", and "cell adhesion molecules" were possessed in top enriched pathways between RGV and ADRV infected groups at $7 \mathrm{dpi}$. The pathway "Antigen processing and presentation" was enriched in RGV-7d but not ADRV-7d. The enriched pathway analysis revealed the differences in immune related pathways in host responses to two viruses invading.

For the top enriched KEGG pathways between RGV infected groups at $1 \mathrm{dpi}$ and $7 \mathrm{dpi}$, "hematopoietic cell lineage" and "cytokine-cytokine receptor interaction" were the 2 common pathways for both comparisons. 10 significantly enriched pathways were identical between ADRV infected groups at $1 \mathrm{dpi}$ and $7 \mathrm{dpi}$, including "cytokine-cytokine receptor interaction", "hematopoietic cell lineage", "malaria", "transcriptional misregulation in cancer", "rheumatoid arthritis", "Jak-STAT signaling pathway", "AGE-RAGE signaling pathway in diabetic complications", "toll-like receptor signaling pathway", 


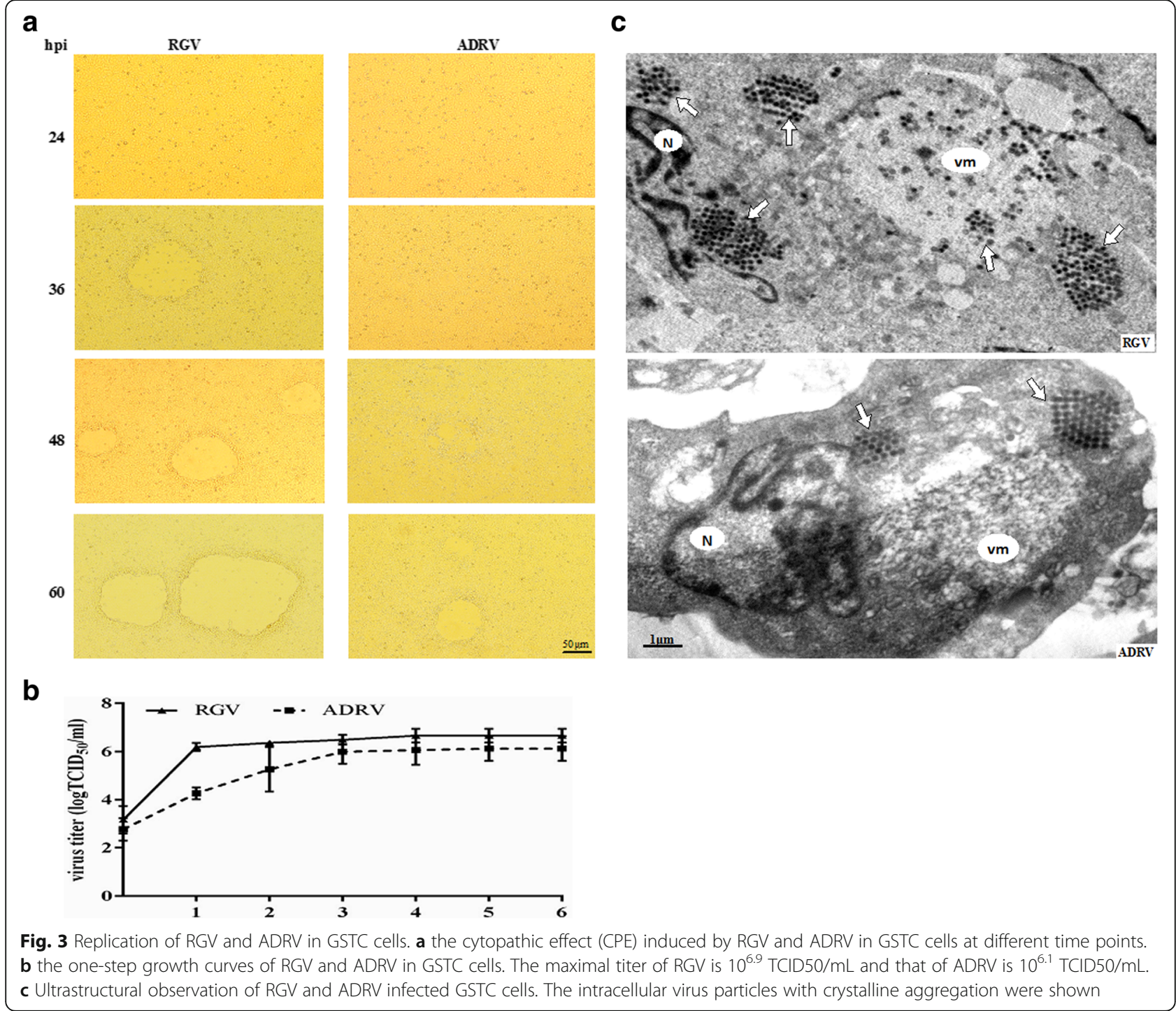

"leishmaniasis", and "complement and coagulation cascades" (Table 2). Detailed information of all the enriched KEGG pathways was collected in Additional file 5: Table S9-S12. Obviously, the host responses to specific virus were divergent at different time periods.

\section{Immune related DEGs and pathways involved in interspecies and natural infection}

The DEGs related to immune pathways were selected for further analysis. For RGV-1d, 31 unigenes were identified as DEGs related to immune pathway with 30 upregulated, while 52 unigenes (37 up-regulated) were identified in ADRV-1d. All of DEGs in RGV-1d except 3 were also found as DEGs in ADRV-1d. For RGV-7d, there were 61 DEGs (34 up-regulated) related to immune pathway, while 166 DEGs (109 up-regulated) were identified in ADRV-7d. The top DEGs were shown in the Table 3. 3 unigenes with homologies to Antigen peptide transporter 2 (TAP2), a member of the superfamily of ATP-binding cassette $(\mathrm{ABC})$ transporters, were highly up-regulated in all comparisons. It indicated that some components involved in antigen processing and presentation were activated by both viruses all the time. Detailed information of all DEGs related to immune pathway was shown in Additional file 6: Table S13-S16.

A total of 7 immune pathways were found significantly enriched by KEGG enrichment analysis of these DEGs. RGV-1d and ADRV-1d both had enriched pathways "hematopoietic cell lineage (HCL)" and "toll-like receptor signaling pathway (TLR)". However, the pathways "complement and coagulation cascades (CCC)" and "antigen processing and presentation (APP)" were only found in ADRV-1d. For RGV-7d and ADRV-7d, the 2 pathways "HCL" and "natural killer cell mediated cytotoxicity (NKC)" were enriched in both comparisons, while the pathways "TLR", "CCC", "intestinal immune 


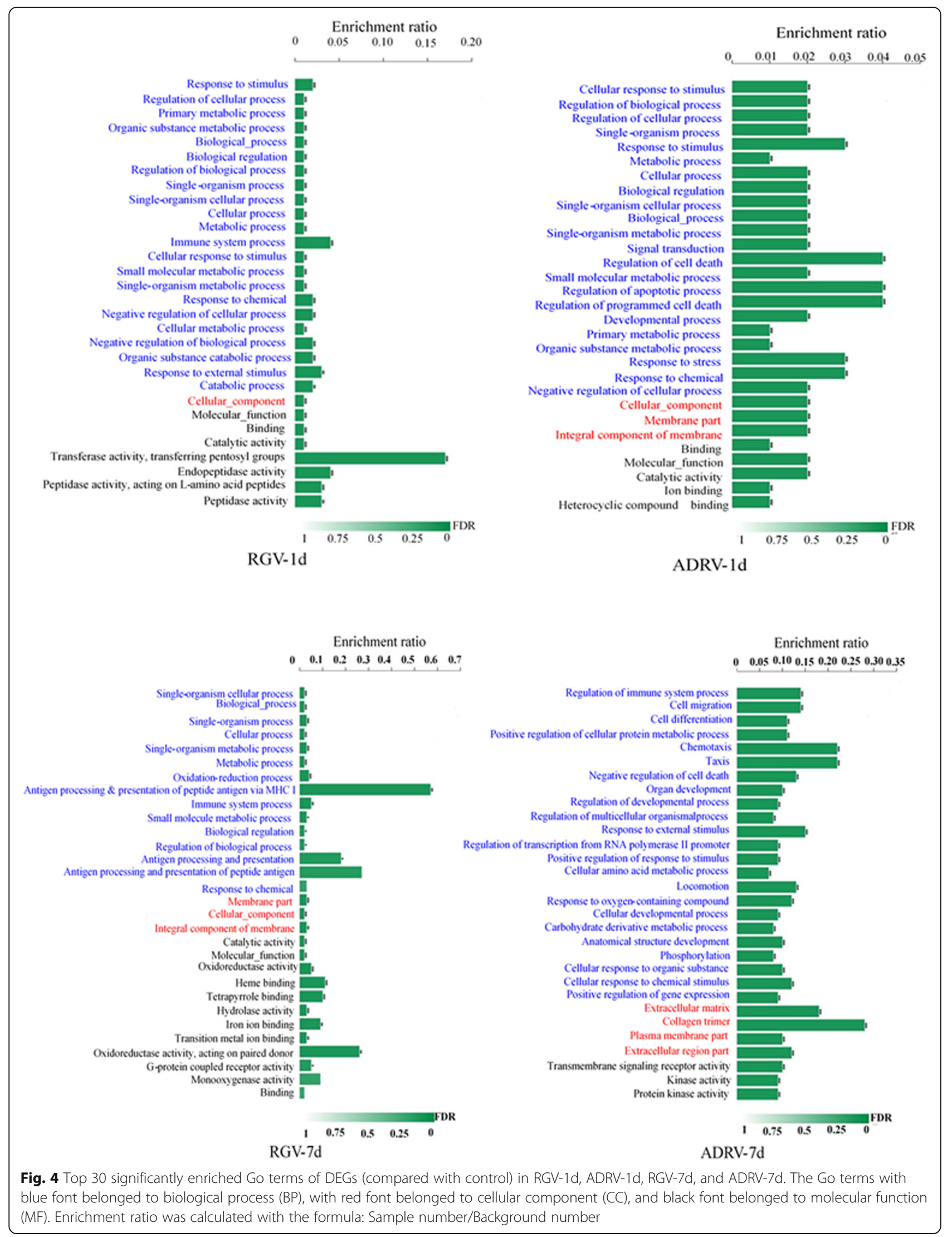


Table 2 Significantly enriched KEGG pathways in CGS under interspecies and natural pathogen infection

\begin{tabular}{|c|c|c|c|c|c|c|c|}
\hline \multicolumn{2}{|l|}{$\overline{R G V-1 d}$} & \multicolumn{2}{|l|}{ ADRV-1d } & \multicolumn{2}{|l|}{ RGV-7d } & \multicolumn{2}{|l|}{ ADRV-7d } \\
\hline KEGG & $p$-values & KEGG & $P$-values & $\overline{K E G G}$ & $P$-values & KEGG & $P$-values \\
\hline $\begin{array}{l}\text { TNF signaling } \\
\text { pathway }\end{array}$ & $6.76 \mathrm{E}-05$ & $\begin{array}{l}\text { Cytokine-cytokine } \\
\text { receptor interaction }\end{array}$ & $3.02 \mathrm{E}-08$ & $\begin{array}{l}\text { Hematopoietic } \\
\text { cell lineage }\end{array}$ & 0.006444 & $\begin{array}{l}\text { Cytokine-cytokine } \\
\text { receptor interaction }\end{array}$ & $1.78 \mathrm{E}-09$ \\
\hline $\begin{array}{l}\text { Cytokine-cytokine } \\
\text { receptor interaction }\end{array}$ & 0.000262 & Malaria & $6.89 \mathrm{E}-05$ & $\begin{array}{l}\text { Cytokine-cytokine } \\
\text { receptor interaction }\end{array}$ & 0.006444 & $\begin{array}{l}\text { Hematopoietic } \\
\text { cell lineage }\end{array}$ & $6.46 \mathrm{E}-07$ \\
\hline Malaria & 0.001122 & $\begin{array}{l}\text { Hematopoietic } \\
\text { cell lineage }\end{array}$ & 0.000204 & $\begin{array}{l}\text { Antigen processing } \\
\text { and presentation }\end{array}$ & 0.006444 & $\begin{array}{l}\text { NF-kappa B } \\
\text { signaling pathway }\end{array}$ & $5.46 \mathrm{E}-05$ \\
\hline $\begin{array}{l}\text { Rheumatoid } \\
\text { arthritis }\end{array}$ & 0.002056 & $\begin{array}{l}\text { Transcriptional } \\
\text { misregulation in cancer }\end{array}$ & 0.000258 & $\begin{array}{l}\text { Cell adhesion } \\
\text { molecules }\end{array}$ & 0.006444 & Malaria & 0.000397 \\
\hline $\begin{array}{l}\text { Hematopoietic } \\
\text { cell lineage }\end{array}$ & 0.002056 & $\begin{array}{l}\text { Jak-STAT signaling } \\
\text { pathway }\end{array}$ & 0.000330 & $\begin{array}{l}\text { Primary } \\
\text { immunodeficiency }\end{array}$ & 0.006444 & $\begin{array}{l}\text { Rheumatoid } \\
\text { arthritis }\end{array}$ & 0.001960 \\
\hline $\begin{array}{l}\text { Jak-STAT signaling } \\
\text { pathway }\end{array}$ & 0.003073 & $\begin{array}{l}\text { TNF signaling } \\
\text { pathway }\end{array}$ & 0.000506 & $\begin{array}{l}\text { Natural killer cell } \\
\text { mediated cytotoxicity }\end{array}$ & 0.008181 & $\begin{array}{l}\text { Jak-STAT signaling } \\
\text { pathway }\end{array}$ & 0.004337 \\
\hline $\begin{array}{l}\text { Transcriptional } \\
\text { misregulation } \\
\text { in cancer }\end{array}$ & 0.020116 & $\begin{array}{l}\text { Antigen processi } \\
\text { and presentation }\end{array}$ & 0.000970 & $\begin{array}{l}\text { Graft-versus-host } \\
\text { disease }\end{array}$ & 0.020223 & $\begin{array}{l}\text { AGE-RAGE signaling } \\
\text { pathway in diabetic } \\
\text { complications }\end{array}$ & 0.007612 \\
\hline Legionellosis & 0.021996 & $\begin{array}{l}\text { Rheumatoid } \\
\text { arthritis }\end{array}$ & 0.001018 & $\begin{array}{l}\text { Glutathione } \\
\text { metabolism }\end{array}$ & 0.036874 & $\begin{array}{l}\text { Complement and } \\
\text { coagulation cascades }\end{array}$ & 0.008071 \\
\hline $\begin{array}{l}\text { Adipocytokine } \\
\text { signaling pathway }\end{array}$ & 0.029942 & $\begin{array}{l}\text { AGE-RAGE signaling } \\
\text { pathway in diabetic } \\
\text { complications }\end{array}$ & 0.004286 & & & $\begin{array}{l}\text { Natural killer cell } \\
\text { mediated cytotoxicity }\end{array}$ & 0.013214 \\
\hline $\begin{array}{l}\text { Osteoclast } \\
\text { differentiation }\end{array}$ & 0.029942 & African trypanosomiasis & 0.016042 & & & Measles & 0.019046 \\
\hline $\begin{array}{l}\text { NF-kappa B } \\
\text { signaling pathway }\end{array}$ & 0.030993 & $\begin{array}{l}\text { Toll-like receptor } \\
\text { signaling pathway }\end{array}$ & 0.025041 & & & $\begin{array}{l}\text { Cell adhesion } \\
\text { molecules }\end{array}$ & 0.020083 \\
\hline $\begin{array}{l}\text { Toll-like receptor } \\
\text { signaling pathway }\end{array}$ & 0.030993 & Legionellosis & 0.025041 & & & $\begin{array}{l}\text { Transcriptional misregulation } \\
\text { in cancer }\end{array}$ & 0.022477 \\
\hline \multirow{8}{*}{$\begin{array}{l}\text { AGE-RAGE signaling } \\
\text { pathway in diabetic } \\
\text { complications }\end{array}$} & 0.030993 & Leishmaniasis & 0.026544 & & & Leishmaniasis & 0.022477 \\
\hline & & Herpes simplex infection & 0.036416 & & & Hepatitis C & 0.022477 \\
\hline & & $\begin{array}{l}\text { Complement and } \\
\text { coagulation cascades }\end{array}$ & 0.038546 & & & $\begin{array}{l}\text { Intestinal immune } \\
\text { network for IgA } \\
\text { production }\end{array}$ & 0.022477 \\
\hline & & & & & & $\begin{array}{l}\text { RIG-I-like receptor } \\
\text { signaling pathway }\end{array}$ & 0.026331 \\
\hline & & & & & & Allograft rejection & 0.033481 \\
\hline & & & & & & $\begin{array}{l}\text { Staphylococcus } \\
\text { aureus infection }\end{array}$ & 0.038645 \\
\hline & & & & & & $\begin{array}{l}\text { Toll-like receptor } \\
\text { signaling pathway }\end{array}$ & 0.046413 \\
\hline & & & & & & $\begin{array}{l}\text { Epithelial cell signaling } \\
\text { in Helicobacter pylori } \\
\text { infection }\end{array}$ & 0.047717 \\
\hline
\end{tabular}

Only 8 KEGG pathways were significantly enriched in RGV-7d. The same KEGG pathways between two groups at the same time points were indicated with bold font

network for IgA production (III)", and "RIG-I-like receptor signaling pathway (RIG)" were enriched in ADRV$7 \mathrm{~d}$, and the pathway "APP" was enriched in RGV-7d (Table 1). It was found that the pathway "HCL" was significantly enriched in all the four comparisons, and the pathway "CCC" was only significantly enriched in ADRV groups.
Regulation of specific host immune related genes by natural pathogen infection

DEGs related to the 5 significantly enriched immune pathways (HCL, TLR, CCC, APP, and NKC) that were found in at least 2 groups were selected for further investigation. The significantly enriched DEGs were mapped to specific positions of the 5 pathways. As 
Table 3 Top 10 up- and down-regulated DEGs of CGS related to immune response. Only 1 down-regulated DEG was found in RGV-1d

\begin{tabular}{|c|c|c|c|c|c|c|c|c|}
\hline & RGV-1d & & ADRV-1d & & RGV-7d & & ADRV-7d & \\
\hline & $\begin{array}{l}\text { Unigene ID } \\
\text { (Gene symbol) }\end{array}$ & $\log _{2} \mathrm{FC}$ & $\begin{array}{l}\text { Unigene ID } \\
\text { (Gene symbol) }\end{array}$ & $\log _{2} \mathrm{FC}$ & $\begin{array}{l}\text { Unigene ID } \\
\text { (Gene symbol) }\end{array}$ & $\log _{2} \mathrm{FC}$ & $\begin{array}{l}\text { Unigene ID } \\
\text { (Gene symbol) }\end{array}$ & $\log _{2} \mathrm{FC}$ \\
\hline Up & c175700_g1 (ABCB3) & 6.58 & c175700_g1 (ABCB3) & 6.69 & c175700_g1 (ABCB3) & 8.2 & C250155_g1 (IFNa) & 6.92 \\
\hline & c175700_g11 (ABCB3) & 6.45 & c175700_g11 (ABCB3) & 6.63 & c175700_g11 (ABCB3) & 7.98 & c175700_g1 (ABCB3) & 6.32 \\
\hline & c175700_g3 (ABCB3) & 5.85 & c175700_g3 (ABCB3) & 6.48 & c175700_g8 (ABCB3) & 7.71 & c175700_g11 (ABCB3) & 6 \\
\hline & c145887_g1 (IL1R2) & 4.41 & c165419_g4 (IL6) & 4.38 & c175700_g3 (ABCB3) & 7.51 & c255707_g1 (MHCl-2) & 5.96 \\
\hline & c227211_g1 (CCL3) & 3.49 & c171455_g1 (CSF3) & 4.34 & c255707_g1 (MHCl-2) & 6.73 & c175700_g3 (ABCB3) & 5.26 \\
\hline & c165419_g4 (IL6) & 3.44 & c145887_g1 (IL1R2) & 4.22 & c178187_g8 (MYLK) & 3.46 & c165419_g4 (IL6) & 5.02 \\
\hline & c171455_g1 (CSF3) & 3.25 & c130377_g1 (FOS) & 3.85 & c6198_g1 (CD142) & 2.36 & c171455_g1 (CSF3) & 4.85 \\
\hline & c182194_g4 (CD45) & 3.07 & C119826_g1 (IL8) & 3.32 & C171449_g1 (A2M) & 2.27 & c227211_g1 (CCL3) & 4.85 \\
\hline & c141851_g1 (TLR5) & 3.02 & c141851_g1 (TLR5) & 3.07 & c131872_g1 (CFB) & 2.17 & c180346_g1 (ISG15) & 4.42 \\
\hline & c6198_g1 (CD142) & 2.68 & c6198_g1 (CD142) & 2.91 & C145563_g1 (PAK1) & 1.96 & c119826_g1 (IL8) & 4.06 \\
\hline Down & c140191_g3 (ARRB) & -1.66 & c140191_g3 (ARRB) & -1.51 & c172210_g1 (COL3A) & -2.81 & c166111_g1 (CD23) & -3.41 \\
\hline & & & c152516_g3 (TNFSF10) & -1.48 & c175190_g1 (CD72) & -2.25 & c140191_g3 (ARRB) & -3.12 \\
\hline & & & c148919_g1 (ITGA6) & -1.43 & c140191_g3 (ARRB) & -2.21 & c172210_g1 (COL3A) & -2.55 \\
\hline & & & c174569_g4 (CCR8) & -1.43 & c157255_g1 (CD46) & -1.83 & c161191_g1 (FLT3) & -2.1 \\
\hline & & & c100947_g1 (CCL3) & -1.35 & c174569_g4 (CCR8) & -1.77 & c181051_g1 (TLR8) & -2.1 \\
\hline & & & c62459_g1 (C3) & -1.35 & c50156_g1 (CD8B) & -1.64 & c50156_g1 (CD8B) & -2.07 \\
\hline & & & c161191_g1 (FLT3) & -1.21 & c204796_g1 (IGH) & -1.62 & c174659_g4 (GZMB) & -1.99 \\
\hline & & & c161569_g1 (VCAM1) & -1.18 & C96738_g1 (CXCR3) & -1.45 & c256484_g1 (RPB10) & -1.87 \\
\hline & & & C169679_g1 (PRF1) & -1.18 & c178769_g7 (LCK) & -1.34 & c147656_g1 (ITGB7) & -1.82 \\
\hline & & & c171198_g1 (MHCl-1) & -1.16 & c181447_g2 (CD8A) & -1.34 & c4388_g1 (CFL) & -1.72 \\
\hline
\end{tabular}

shown in Fig. 5 and Additional file 7-S17-S21, compared with RGV, ADRV infection alone induced the up-regulation of CR1 and C5AR1 at $1 \mathrm{dpi}$, which was related to phagocytosis and degranulation, but the down-regulation of MHC I-1 (Unigene 1 of MHC I), CD8A, and CD8B, which were key components in antigen processing and presentation. Both RGV and ADRV infection induced the up-regulation of cytokines at $1 \mathrm{dpi}$, such as IL6, IL8, TNF $\alpha$, and CD114, which could benefit the neutrophil formation and proinflammatory and chemotactic effects. For samples at $7 \mathrm{dpi}$, RGV infection alone induced the upregulation of CD35, GZMB-1, MHC I-3 (Unigene 3 of MHC I) and down-regulation of IL1 $\beta$. Besides upregulation of genes related to neutrophil formation, proinflammatory and chemotactic effects, and phagocytosis, ADRV infection induced up-regulation of genes related to fibrin degradation (F5 and F10) and antiviral effects (IFN $\alpha$ ), and down-regulation of MHC I-1 compared with RGV. In addition, RGV and ADRV infection induced the up-regulation of TRAILR and down-regulation of perforin (related to apoptosis), upregulation of $\mathrm{MHC} \mathrm{I}-2$ (Unigene 2 of $\mathrm{MHC} \mathrm{I}$ ) and the down-regulation of $\mathrm{IgH}$ and $\mathrm{CD} 8$ (related to $\mathrm{B}$ cell and $\mathrm{T}$ cell).
The MHC class I pathway and Coagulation cascades were further selected from KEGG pathways. As shown in Fig. 6a, RGV infection induced the up-regulation of TNF $\alpha$, HSP90, and TAP1/2 at 1 dpi. However, ADRV infection induced the down-regulation of MHC I-1 and CD8 (A, B) besides the up-regulation of the genes same as RGV infection. The phenomenon revealed that this pathway was not significantly changed in RGV-1d, because the key downstream molecules MHC I and CD8 were not DEGs in this group. But ADRV activated this pathway with inhibition of MHC I and CD8 expression. For genes related to Coagulation cascades, only 2 genes up-regulated in RGV-7d, while 8 genes up-regulated in ADRV-7d including F10, F5, and Fibrinogen (Fig. 6b). It was consistent with the fact that no hemorrhage symptom was observed in RGV infected CGS compared with ADRV.

\section{Expression of representative virus genes and host DEGs}

The selected virus genes, RGV-89R and ADRV-26 L (homologues of ranavirus immediately early protein 18 , ICP18), RGV-44R and ADRV-68 L, and RGV-24R and ADRV-88 L, were detected in corresponding samples infected by RGV or ADRV, although expression level in some samples was very low. The expression level of detected viral genes was higher in RGV-1d than that in 


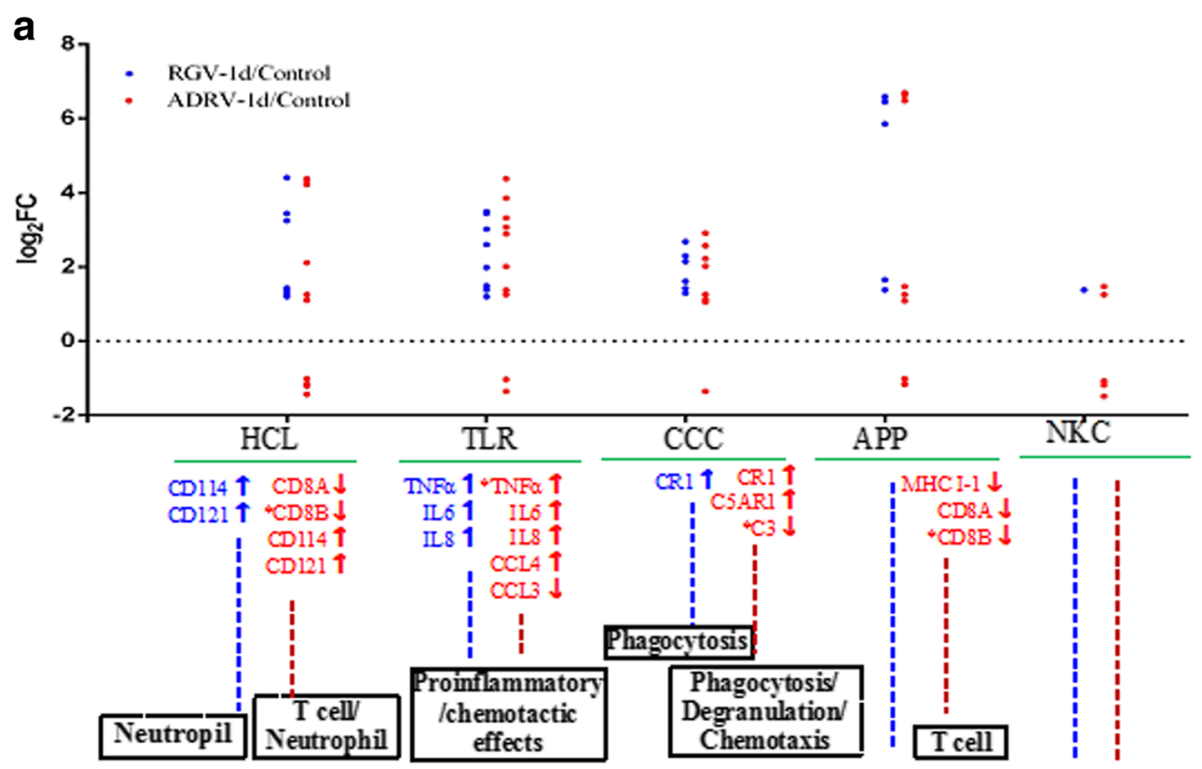

b

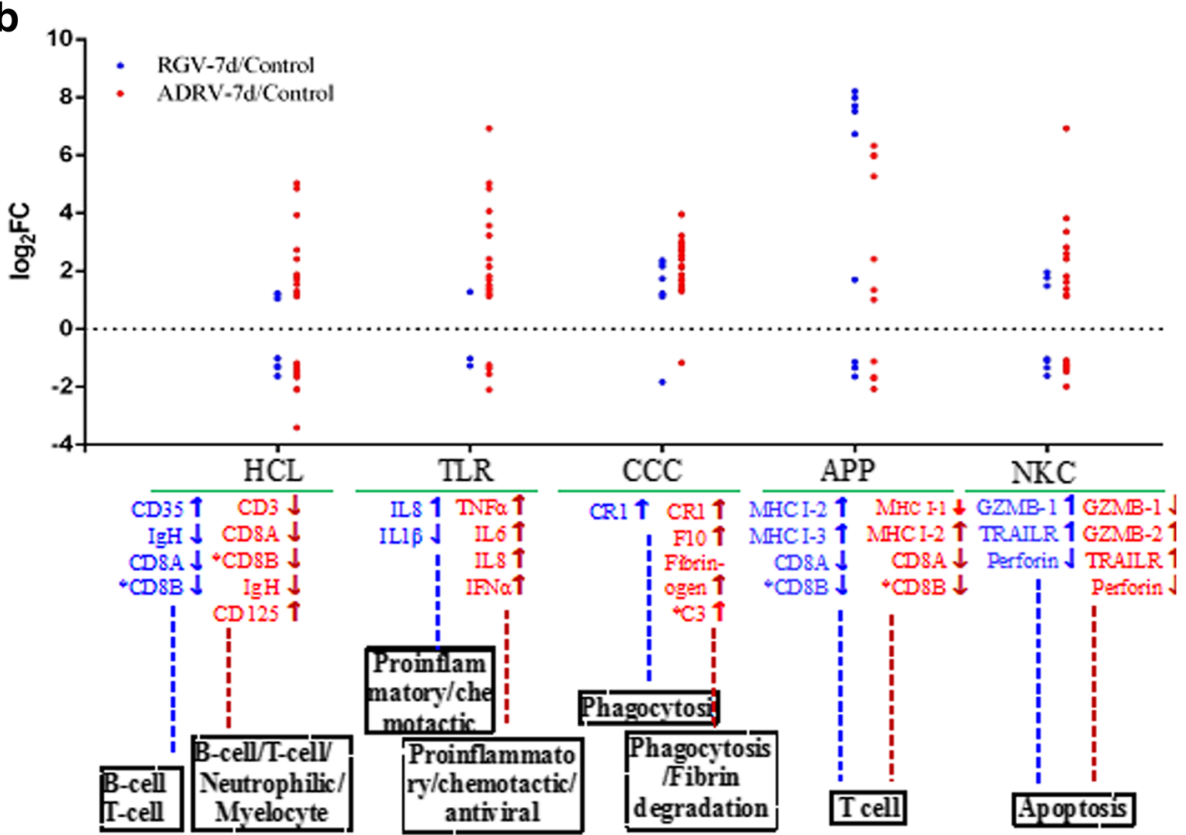

Fig. 5 Scatter plots of expression patterns of specific DEGs. DEGs in significantly enriched KEGG pathways related to immune response at 1 dpi (a) and $7 \mathrm{dpi}$ (b) were selected for analysis. HCL: Hematopoietic cell lineage; TLR: Toll-like receptor signaling pathway; CCC: Complement and coagulation cascades; APP: Antigen processing and presentation; NKC: Natural killer cell mediated cytotoxicity. Each spot indicates a DEG. Key DEGs between ADRV and RGV groups were shown below the scatter plots with different font colors (blue font indicates RGV group and red font indicates ADRV group). Up-regulated DEGs were marked with " $\uparrow$ " and down-regulated DEGs were shown with " $\downarrow$ ". The genes that were detected by RT-qPCR were marked with "*". Possible functions or targets of the pathway were indicated in dashed box

ADRV-1d, but it was lower in RGV-7d than that in ADRV-7d. RGV-89R (homologue of ICP18) had the highest expression level in RGV-1d among the four groups (especially compared with ADRV $26 \mathrm{~L}$ ), while ADRV $68 \mathrm{~L}$ and $88 \mathrm{~L}$ had the highest expression levels in ADRV-7d (compared with its RGV homologues). Expression of host genes (TNF $\alpha, \mathrm{CD} 8 \mathrm{~B}$, and $\mathrm{C} 3$ ) was also detected in all samples. TNF $\alpha$ is an important cell signaling protein involved in the pathway "HCL", "TLR", "APP", and "NKC". CD8B is mainly expressed on the surface of cytotoxic T cell. C3 has a central role in the complement system. Expression of TNF $\alpha$ was largely up-regulated in RGV-1d, ADRV-1d, and ADRV$7 \mathrm{~d}$, while the expression of CD8B was down-regulated in RGV-7d, ADRV-1d, and ADRV-7d. The upregulation of genes related to "complement and 


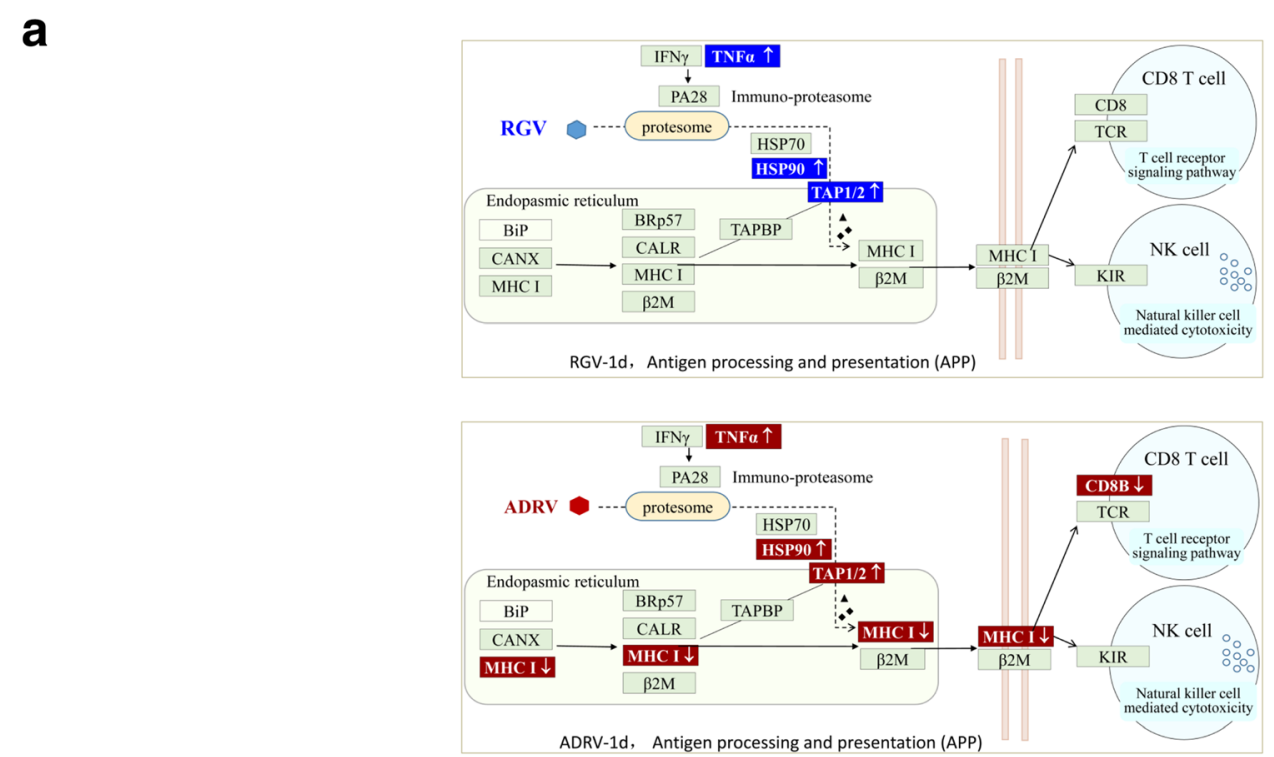

b
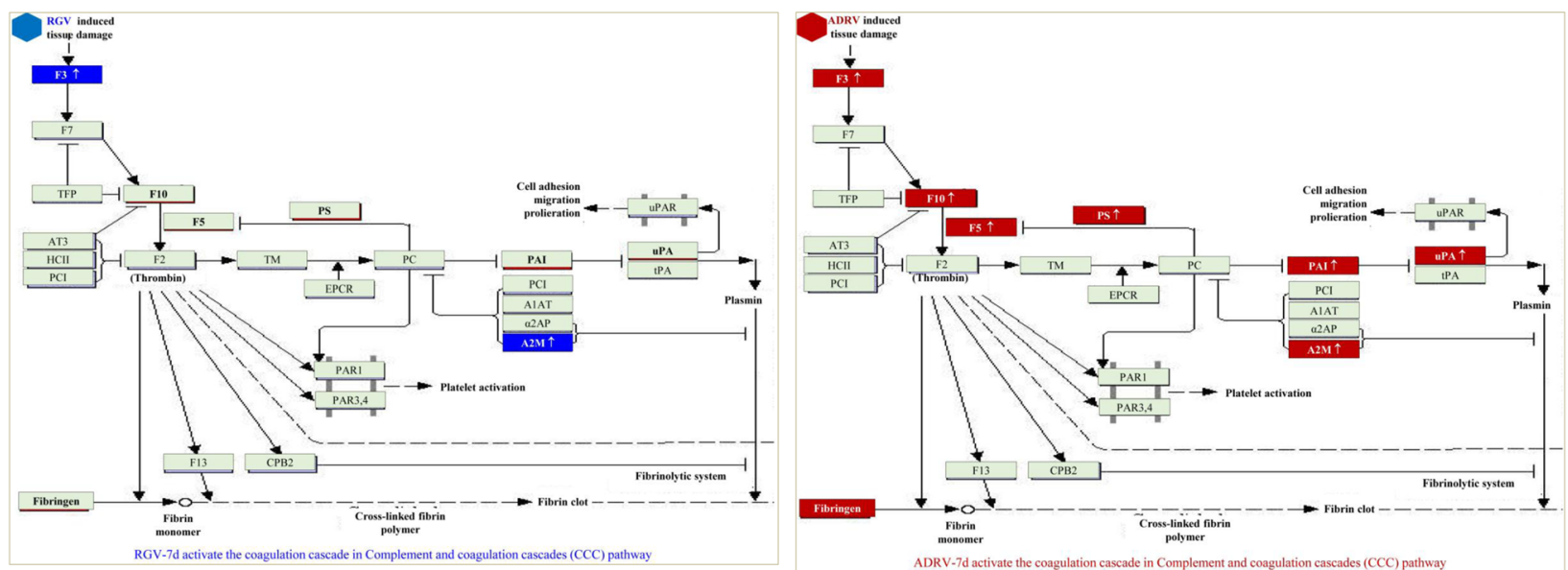

Fig. 6 Significantly enriched DEGs in specific KEGG pathways. a MHC class I pathway of the KEGG pathway "Antigen processing and presentation" at 1 dpi. $\mathbf{b}$ coagulation cascades of the KEGG pathway "Complement and coagulation cascades" at 7 dpi. Enriched DEGs of the present study were marked with blue color (RGV) and red color (ADRV). Up- and down-regulated DEGs were marked with " $\uparrow$ " and " $\downarrow$ ", respectively

coagulation cascades" (such as C3) at ADRV-7d were also revealed (Fig. 7).

\section{Discussion}

Aquaculture in China has been believed to be a major contribution to the world [10]. But its development has been hampered by viral diseases. As members belonging to one of the most primitive orders of the urodele amphibians, CGS has high academic values in researches about evolution and biodiversity [37]. Besides, it has been cultured in different regions of China as part of the aquaculture industry. However, it is easy to suffer from ranaviruses, leading to mass mortalities [12, 32, 40], which could be related to the wide host range of ranaviruses [15], and the interactions with different ranaviruses in water environment. Whether the interspecies infection occurred in CGS and the virus-host interactions in interspecies infection still remains unknown. Transcriptome contains the global information of RNAs (often mRNA) in specific organisms under a given time, which enables a genome-wide survey of interested genes and gene-networks, has been widely used in biology, medicine, agriculture, and so on [41-43]. In the present study, we tried to explore the overall dynamic changes in large DNA virus interspecies infection by using this tool. The different virus replication rates and variant host responses were revealed.

Paired reads covering virus gene and RT-qPCR showed that the replication and gene expression trends of the two viruses were different. The number of virus genes 


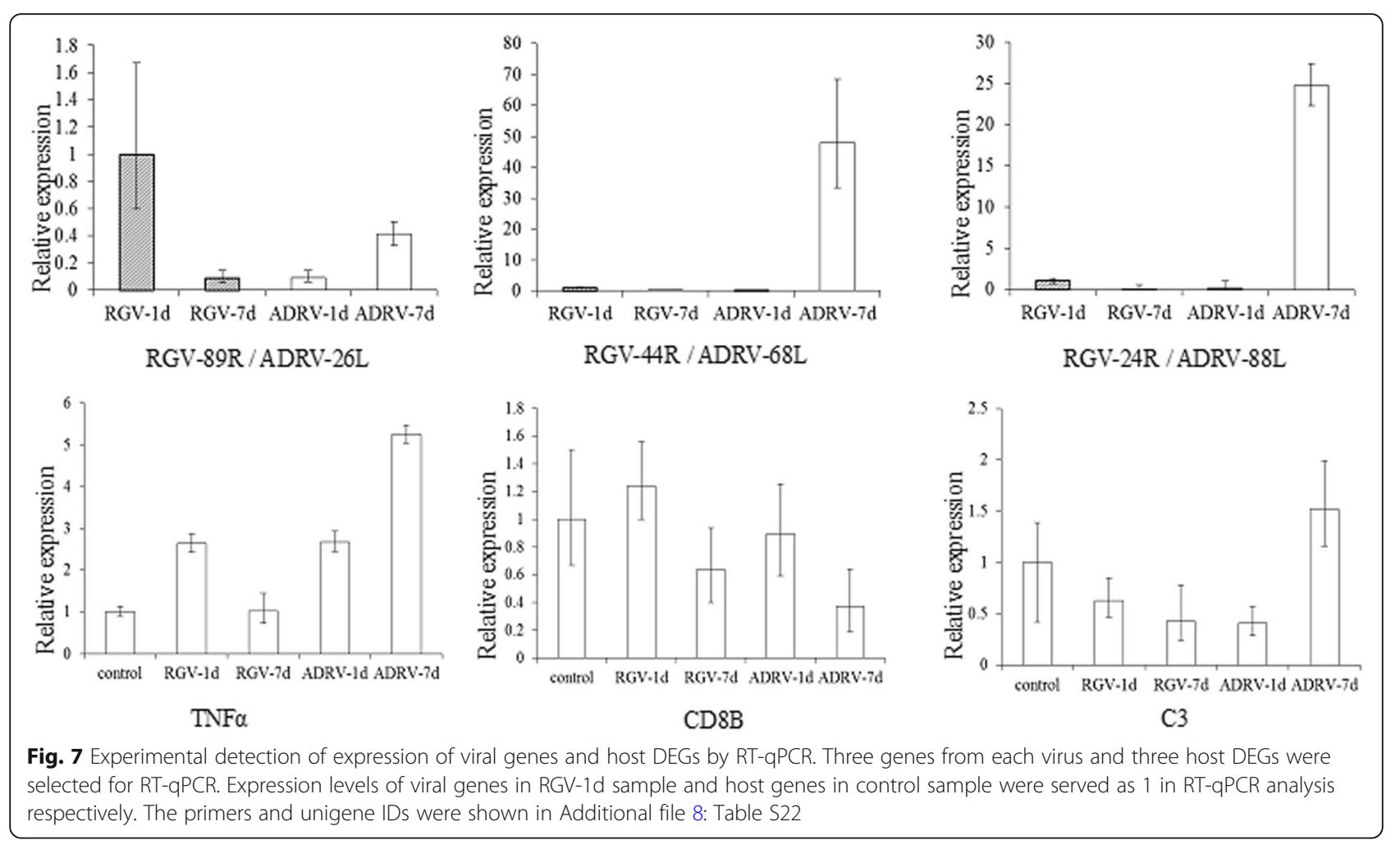

with paired reads and gene expression levels of RGV-1d were all higher than that of ADRV-1d, which suggested the interspecies pathogen replicated faster than natural pathogen at the early stage of infection. This phenomenon, as far as we know, is infrequent in DNA virus interspecies infection. The rapid replication may be an inherent character of RGV, which may be used by DNA virus as a strategy for interspecies infection. The virus replicated rapidly immediately after entry into host cells to get time and space before the unprepared host immune system. In contrast, ADRV may have adapted to CGS under long-term virus-host interactions. It replicated in an unruffled manner. Different viruses may adopt divergent strategies to facilitate their survival. It was easier for RNA virus such as Influenza A virus to adapt and replicate in host because of more frequent mutations and reassortments [44]. However, mutations were fewer in double-stranded DNA viruses than in RNA virus. The high replication rate may be another strategy in large DNA virus infection.

The number of DEGs and immune related pathways of RGV infected group were lower than that of ADRV group, which indicated the host transcriptome responses to RGV was relatively weaker than ADRV. The other interesting phenomenon was that the host responses in RGV-1d were lower than ADRV-1d, which was inconsistent with the virus gene expression. The interspecies pathogen had higher gene expression level, but induced lower host responses than the natural pathogen. Avoiding the overstimulation of host responses could be a strategy for interspecies infection. The exact mechanisms of interactions between RGV and the host need further study. In contrast, different ways were employed by the natural pathogen ADRV. ADRV specifically down-regulated the expression of some host genes, such as MHC I-1 and CD8 (A and B) at the early stage of infection, as well as perforin, a key executor of cytotoxic lymphocytes [45]. MHC class I molecules could present cytosol peptides to $\mathrm{CD} 8$ positive $\left(\mathrm{CD} 8^{+}\right)$cytotoxic $\mathrm{T}$ cells [46]. $\mathrm{CD}^{+} \mathrm{T}$ cells are crucial components of cellmediated immune responses for providing protection against viral infections [47]. This phenomenon could explain the differences between virus replication in vitro and in vivo, for the T cells are lacked in cultured GSTC cells. Nevertheless, ADRV induced a more intense response in host though inhibition of some immune related genes. RGV avoided to over-stimulating host immune system at the early stage of infection, but strong immune responses were activated with the time went on because more immune related pathway such as APP and NKC were significantly enriched in RGV-7d. Based on these observations, we speculate that different outcomes for the two viruses may be gained after a period of infection. RGV may be eliminated or released from CGS and infect its natural host frog again. It also could achieve a balance with CGS and persist in it. The other possibility 
for RGV is that it evolved and adapted to CGS, and then interspecies transmission occurs. RGV might exist for a long time in CGS after the early infection, for the viral reads appeared at $7 \mathrm{dpi}$, which would facilitate the virus adaptation and the exchange of genetic materials between different viruses [48]. Different host susceptibility and longtime persistence have been reported in other ranaviruses [27, 49-51]. The possibilities of RGV during its infection need to be proved in the future.

Expression level of DEGs in the pathway "complement and coagulation cascades" was divergent between RGV$7 \mathrm{~d}$ and ADRV-7d. The complement system is an important part of the innate immunity that contains at least 35 or more plasma proteins and cell surface receptors/regulators [52]. This system could recognize and eliminate invaders such as viruses. On the other hand, viruses have also developed multiple strategies against the complement system [53]. At later stage of infection, the system was activated by the abundant replication of viruses. Fewer up-regulated complement system genes of RGV$7 d$ than that of ADRV-7d was in accordance with the fact that the expression level of RGV gene was lower than that of ADRV at $7 \mathrm{dpi}$. It has been reported that hyperactivity of the complement system can lead to endothelial and blood cell damage, which would give rise to hemolysis, platelet activation and aggregation, and prothrombotic and inflammatory changes [54, 55]. Thus, the up-regulation of genes in complement system at later stage of ADRV infection may be involved in the systemic hemorrhage of diseased CGS, which was also reflected by the up-regulation of genes in "Coagulation cascades".

Innate and adaptive immune system have been reported to involve in ranavirus-host interactions [56-60]. Although high genome sequence colinearity and similarity were found between RGV and ADRV [32], the differences in their gene expression and amino acids sequences might result in different immune responses in vivo. It has been reported that cytomegalovirus could inhibit antigen presentation to $\mathrm{T}$ cells [61]. The viral host shutoff proteins of some herpesviruses could degrade host MHC class I mRNA to interfere the MHC class I-mediated peptide presentation [62]. Further study about the interactions between RGV/ADRV and $\mathrm{MHC} \mathrm{I/CD8}{ }^{+} \mathrm{T}$ cells would benefit the understanding of interspecies infection. The polymorphism of MHC I and functions of its isoforms should also be investigated. Some proteins of ranaviruses have been identified as antagonist to mediate host immunity, such as homologs of eukaryotic translation initiation factor 2 alpha $(\mathrm{eIF}-2 \alpha)[18,63,64]$. The finding that ADRV encodes a full length eIF2 $\alpha$-like protein (ORF84L) but RGV encodes a truncated homolog (ORF28R) enhanced our interest to explore the different virus-host interactions in the future.

\section{Conclusions}

In conclusion, different strategies were employed by the two viruses in interspecies and natural infection of CGS, which then induced divergent host responses in transcriptional levels. RGV replicated rapidly and avoided to overstimulating host immune system in interspecies infection. In contrast, the natural pathogen ADRV had a moderate replication rate with the inhibition of pivotal components of host immune system. However, stronger immune responses were activated in interspecies infection as time went on, which then lead to different fate for RGV. Abundant proliferation of ADRV occurred because of the inhibition of host immunity, which then led to stronger host responses. After a period of infection, different outcomes for the two viruses may be gained (Fig. 8).

\section{Methods}

\section{Viruses and interspecies infection in vitro and in vivo}

RGV that isolated from diseased pig frog Rana grylio [36] was used as non-natural pathogen for interspecies infection. At the same time, ADRV that isolated from CGS [32] was used for comparison as natural pathogen in the present study.

For detection of interspecies infection in vitro, Onestep virus growth curves of RGV were performed in CGS thymus cell (GSTC) line as described previously [39]. Briefly, GSTC cells were grown in 96-well plates and infected with RGV at an m.o.i of 0.1. The cells were harvested at various intervals $(0,1 \mathrm{~d}, 2 \mathrm{~d}, 3 \mathrm{~d}, 4 \mathrm{~d}, 5 \mathrm{~d}$, and $6 \mathrm{~d})$ and titrated on duplicate monolayers of GSTC cells. The one-step virus growth curve of ADRV was also performed under same conditions.

Ultrastructural observation was performed as described by Huang et al. [28]. GSTC cells were infected with RGV and ADRV respectively. At $1 \mathrm{dpi}$, the cells were harvested and collected by centrifugation. The pellets were fixed with $2.5 \%$ glutaraldehyde, followed by $1 \%$ OsO4. After dehydrated with ethanol, the cells were embedded in Epon-812, and then were sectioned and stained. The ultra-thin sections were examined with a JEM-1230 electron microscopy at $100 \mathrm{kV}$ and micrographs were taken by CCD camera.

For interspecies infection in vivo, health cultured CGSs of $95 \mathrm{~g}$ mean mass were obtained from a farm in Jiangxi, China, and acclimated in aerated dechlorinated water at $22{ }^{\circ} \mathrm{C}$ for 2 weeks before initiation of the experiment. The animals were fed with commercial feed and water was replaced daily.

After 2 weeks acclimation, health CGSs were randomly selected to perform interspecies infection. Six CGSs were intraperitoneally injected with $200 \mu \mathrm{l} \mathrm{RGV}\left(6 \times 10^{6}\right.$ $\mathrm{TCID}_{50}$ ) respectively and the other six CGSs were injected with $200 \mu \mathrm{l}$ ADRV $\left(6 \times 10^{6} \mathrm{TCID}_{50}\right)$ under same 


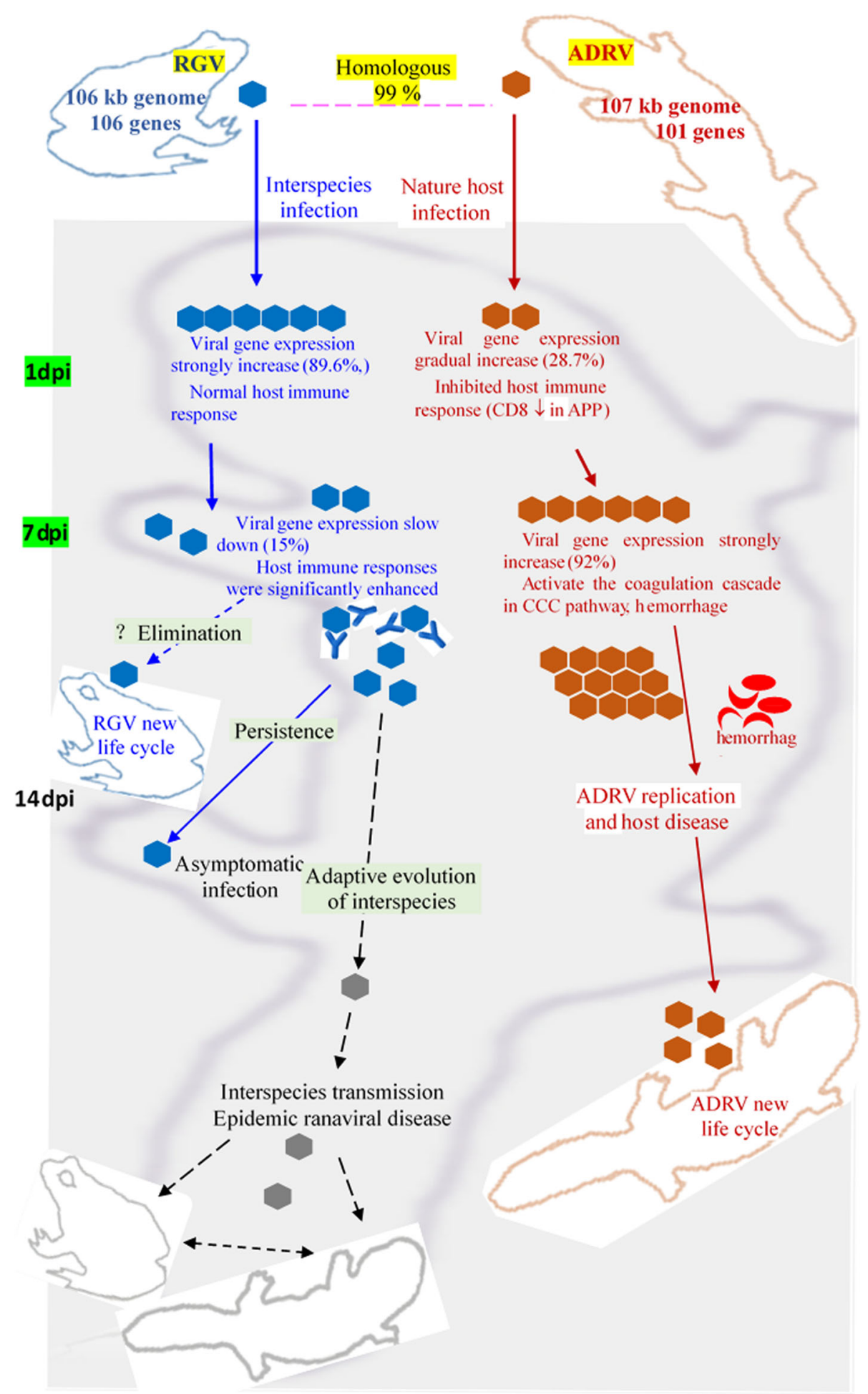

Fig. 8 Illustration of CGS under interspecies and natural pathogen infection. Events occurred in RGV infection were shown in blue color and that related to ADRV was shown in red color. The events that proved in the present study were indicated by solid arrows, whereas that might occur were indicated by dotted arrows 
operations. Another three were injected with $200 \mu \mathrm{l}$ PBS each as control.

At 1 day post-injection (dpi), spleens were collected from three individuals of RGV injected CGSs and denoted as RGV-1d. Simultaneously, spleens were collected from three individuals of ADRV and PBS injected CGSs and recorded as ADRV-1d and Control, respectively. At $7 \mathrm{dpi}$, spleens were collected from RGV and ADRV injected CGSs as described above and recorded as RGV-7d and ADRV-7d, respectively.

All surgery was performed under benzocaine anesthesia, and all efforts were made to minimize suffering. Animals were sacrificed by intraperitoneal injection of sodium pentobarbital.

\section{RNA isolation, library construction and sequencing}

Total RNA of collected spleens from 15 individuals (group RGV-1d, RGV-7d, ADRV-1d, ADRV-7d, and Control; $n=3$ ) were extracted with TRizol reagent (Invitrogen, USA) following the manufacturer's protocol. RNA integrity, purity, and concentration were determined by electrophoresis and the NanoDrop 2000 spectrophotometer (ThermoFisher, USA). RNA samples with high quality were used in library construction. Libraries were constructed using the TruseqTM RNA sample prep kit (Illumina, USA) following the manufacturer's protocol. Briefly, mRNA was purified by using poly-T oligo-attached magnetic beads and fragmented with fragmentation buffer. After first and second cDNA synthesis, the cohesive ends of cDNA were repaired and then adenosines were added to the 3' ends. Adapters were ligated to the cDNA and then cDNA fragments were enriched by PCR. PCR products were purified using Certified Low Range Ultra Agarose (Bio-Rad, USA) and quantified with TBS380 Picogreen (Invitrogen, USA). Libraries were sequenced on Illumina HiSeq platform using HiSeq 4000 SBS Kit (Illumina, USA) and generated raw data reads.

\section{Data analysis}

The raw data reads were processed using software SeqPrep and Sickle to remove adapter, poly-N and poor quality data. The resulted data was clean data (clean reads) and its Q20, Q30, and GC contents were calculated to evaluate the data quality. De novo transcriptome assembly was performed using Trinity software [65] based on the clean data. Unigenes acquired from the assembly were annotated to NR, Pfam, String, Swissprot, and KEGG databases by Trinity and BlastX software (E-value cut-off of 1.0E-5).

Expression levels of unigenes were counted using RSEM software [66]. The results (Additional file 8: Table S22) were presented as numbers of fragments per kilobase of transcript per million fragments sequenced
(FPKM) and used for unigene expression analysis. The clean reads were mapped to virus genome using bowtie2 [67]. Number of fragments (paired reads) covering each virus gene were counted using featureCounts [68].

\section{Differential expression analysis}

Differential expression analysis between two groups (virus infected group compared to control) was performed using edgeR package [69] base on the unigenes obtained from Trinity assembly and expression levels from RSEM software. Genes with FDR $<0.05$ and $\mid \log _{2}$ Fold Change $\left(\left|\log _{2} \mathrm{FC}\right|\right) \geq 1$ were assigned as differentially expressed genes (DEGs). Venn diagram was created using VennDiagram [70] to show the quantitative distribution of DEGs in different comparisons. Gene ontology (GO) annotation was performed using blast2go software [71] to classify the DEGs. Pathway analysis was performed using the Kyoto Encyclopedia of Genes and Genomes (KEGG) database [72]. The enrichment analyses of Go terms and KEGG pathways were performed using Goatools [73] and KOBAS [74] based on Fisher's exact test, respectively. Multiple corrections including Bonferroni, Holm, Sidak, and false discovery rate were used for correcting the $P$-value as described by $\mathrm{Lu}$ et al. [75]. Targets with corrected P-value $\leq 0.05$ were assigned as significantly enriched.

\section{Experimental detection of virus genes and host DEGs by RT-qPCR}

Three pairs of virus genes (each pair were homologous: RGV-89R and ADRV-26 L, RGV-44R and ADRV-68 L, and RGV-24R and ADRV-88 L) and three host genes (TNF $\alpha, C D 8 B$, and C3) were selected for real-time quantitative PCR (RT-qPCR) analysis. Primers used in this assay were listed in Additional file 9: Table S23. RNA from the same samples in RNA-Seq was used as templates. First strand cDNA synthesis was performed using PrimeScript RT reagent Kit with gDNA Eraser (TaKaRa, Japan). RT-qPCR was conducted using a StepOne Real-Time PCR system (The Applied Biosystems, USA). Each RT-qPCR mixture contained $1 \mu \mathrm{l}$ of cDNA, $12.5 \mu \mathrm{l}$ of SYBR Premix $(2 \times), 0.5 \mu \mathrm{l}$ of forward and reverse primers (for each primer), and $10.5 \mu \mathrm{l}$ of ultrapure water. The RT-qPCR conditions were as follows: $95{ }^{\circ} \mathrm{C}$ for $10 \mathrm{~min}$; 40 cycles of $95{ }^{\circ} \mathrm{C}$ for $15 \mathrm{~s}$ and $60{ }^{\circ} \mathrm{C}$ for $1 \mathrm{~min}$; and a melt curve analysis at $95{ }^{\circ} \mathrm{C}$ for $15 \mathrm{~s}, 60{ }^{\circ} \mathrm{C}$ for $1 \mathrm{~min}$, and $95{ }^{\circ} \mathrm{C}$ for $15 \mathrm{~s}$. The $\beta$-actin gene was used as internal control. The mRNA relative expression ratios of the treated group versus that of the control group were calculated by the $2^{-\Delta \Delta C T}$ method [76]. 


\section{Additional files}

Additional file 1: Table $\mathbf{S} 1$. The paired reads covering each gene of ADRV in ADRV-1d and ADRV-7d. Table S2. The paired reads covering each gene of RGV in RGV-1d and RGV-7d. GenBank accession number of the virus genome, start and end position of ORF (gene), gene length, counts of each sample were shown. (ZIP $24 \mathrm{~kb}$ )

Additional file 2: Figure S1. Sequence length distribution of unigenes from all libraries. The smallest, largest, average, N50, and N90 length were shown in the figure. (TIFF $148 \mathrm{~kb}$ )

Additional file 3: Table S3. Top 10 DEGs in comparison of RGV-1d/ control and ADRV-1d/control. Table S4. Top 10 DEGs in comparisons of RGV-7d/control and ADRV-7d/control. Unigene IDs of DEGs possessed by two groups (RGV-1d/control and ADRV-1d/control, RGV-7d/control and ADRV-7d/control) were indicated in bold font. "-" means no homolog found. (ZIP $19 \mathrm{~kb}$ )

Additional file 4: Table S5. Detailed information of all the enriched Go terms in RGV-1d/control. Table S6. Detailed information of all the enriched Go terms in ADRV-1d/control. Table S7. Detailed information of all the enriched Go terms in RGV-7d/control. Table S8. Detailed information of all the enriched Go terms in ADRV-7d/control. List of Go terms include the ID and description of Go terms, enrichment ratio, corrected $p$-value, main categories, and enriched DEGsn. (ZIP $339 \mathrm{~kb}$ )

Additional file 5: Table S9. Detailed information of all the enriched KEGG pathways in RGV-1d/control. Table S10. Detailed information of all the enriched KEGG pathways in ADRV-1d/control. Table S11. Detailed information of all the enriched KEGG pathways in RGV-7d/control. Table S12. Detailed information of all the enriched KEGG pathways in ADRV-7d/control. List of KEGG pathways include pathway name, number of DEGs and unigene IDs enriched in corresponding pathway, corrected p-value, and hyperlink of the pathway. (ZIP $124 \mathrm{~kb}$ )

Additional file 6: Table S13. Detailed information of DEGs related to immune pathways in RGV-1d/control. Table S14. Detailed information of DEGs related to immune pathways in ADRV-1d/control. Table S15. Detailed information of DEGs related to immune pathways in RGV-7d/ control. Table S16. Detailed information of DEGs related to immune pathways in ADRV-7d/control. List of DEGs include the sequence ID, counts and fpkm value, $\log _{2}$ fold change, p-value, FDR, and annotations in NR, Swissprot, String, KEGG, and Pfam. (ZIP 99 kb)

Additional file 7: Gene expression in representative immune pathways. Table S17. Gene expression level in the pathway "Hematopoietic cell lineage". Table S18. Gene expression level in the pathway "Toll-like receptor signaling pathway". Table S19. Gene expression level in the pathway "Complement and coagulation cascades". Table S20. Gene expression level in the pathway "Antigen processing and presentation". Table S21. Gene expression level in the pathway "Natural killer cell mediated cytotoxicity". The $\log _{2}$ (fold change) of each DEG assigned to corresponding pathway was shown. (ZIP $45 \mathrm{~kb}$ )

Additional file 8: Table S22. FPKM of all unigenes. (XLSX 14778 kb) Additional file 9: Table S23. Genes and primers used for RT-qPCR. (DOCX $16 \mathrm{~kb}$ )

\section{Abbreviations}

ADRV: Andrias davidianus ranavirus; C3: Complement component 3; C5AR1: Complement component 5a receptor 1; CCL3: Chemokine (C-C motif) ligand 3; CD114: Cluster of Differentiation 114; CD35: Cluster of differentiation 35; CD8B: Cluster of differentiation 8; CGS: Chinese giant salamander; CR1: Complement receptor type 1; DEG: Differentially expressed gene; dpi: Day post-injection; elF-2a: Eukaryotic translation initiation factor 2 alpha; F10: Factor X; F5: Factor V; FLT3: Fms like tyrosine kinase 3; GO: Gene Ontology; GSTC: CGS thymus cell; GZMB: Granzyme B; HSP90: Heat shock protein 90; IFNa: Interferon a; IgH: Immunoglobulin heavy chain; IL1 $\beta$ : Interleukin 1 ;; IL6: Interleukin 6; IL8: Interleukin 8; ITGA6: Integrin alpha-6; KEGG: Kyoto Encyclopedia of Genes and Genomes; $\log _{2}$ FC: $\log _{2}$ Fold Change; MHC I: Major histocompatibility complex class I; ORF: Open reading frame; RGV: Rana grylio virus; RT-qPCR: Real-time quantitative PCR; TAP1/
2: Antigen peptide transporter 1/2; TLR1: Toll-like receptor 1; TNFa: Tumor Necrosis Factor a; TRAILR: TRAIL receptor

\section{Acknowledgements}

Not applicable

\section{Funding}

The National Natural Science Foundation of China (31430091, 31772890), Strategic Pilot Science and Technology of the Chinese Academy of Sciences Project (XDA08030202), Project of State Key Laboratory of Freshwater Ecology and Biotechnology (2016FBZ01). The funders had no role in the design of the study and collection, analysis, and interpretation of data and in writing the manuscript.

\section{Availability of data and materials}

The sequencing data were deposited in the Sequence Read Archive (SRA) at the National Center for Biotechnology Information (NCBI) under the accession number SRP115981.

\section{Authors' contributions}

QYZ and JFG conceived and designed the project and prepared materials for the study. FK and QYZ wrote the manuscript and analyzed the data. ZYC and TL performed sample collection and RNA isolation. CKL performed in vitro infection. FK and ZHW participated in primers design and qPCR analysis. All authors have read and approved the final manuscript.

\section{Ethics approval}

Cultured CGSs were obtained from a farm in Jiangxi, China. The permission for collecting the specimens is not needed in the present study. The specimens are aquaculture animals. The animal procedure and protocol was approved by the Institutional Animal Care and Use Committee of the Institute of Hydrobiology, Chinese Academy of Sciences (Approval number: Y51317-1-301). The statements have been added in the 'Ethics Approval and Consent to Participate' section. All surgery was performed under the efforts made to minimize potential harmful effects.

\section{Consent for publication}

Not applicable

\section{Competing interests}

The authors declare that they have no competing interests.

\section{Publisher's Note}

Springer Nature remains neutral with regard to jurisdictional claims in published maps and institutional affiliations.

Received: 12 October 2017 Accepted: 12 March 2018

Published online: 20 March 2018

References

1. Olsen B, Munster VJ, Wallensten A, Waldenström J, Osterhaus AD, Fouchier RA. Global patterns of influenza a virus in wild birds. Science. 2006;312:384-8.

2. Chan JF, Chan KH, Choi KY, To KKW, Tse H, Cai J, et al. Differential cell line susceptibility to the emerging Zika virus: implications for disease pathogenesis, non-vector-borne human transmission and animal reservoirs. Emerg Microbes Infect. 2016;5:e93.

3. Pappalardo M, Collu F, Macpherson J, Michaelis M, Fraternali F, Wass MN. Investigating Ebola virus pathogenicity using molecular dynamics. BMC Genomics. 2017;18:566.

4. Shi Y, Wu Y, Zhang W, Qi J, Gao GF. Enabling the 'host jump': structural determinants of receptor-binding specificity in influenza a viruses. Nat Rev Microbiol. 2014;12:822-31.

5. Yoon SW, Webby RJ, Webster RG. Evolution and ecology of influenza a viruses. Curr Top Microbiol Immunol. 2014;385:359-75.

6. Holmes EC, Dudas G, Rambaut A, Andersen KG. The evolution of Ebola virus: insights from the 2013-2016 epidemic. Nature. 2016;538:193-200.

7. Rather IA, Lone JB, Bajpai VK, Paek WK, Lim J. Zika virus: an emerging worldwide threat. Front Microbiol. 2017:8:1417.

8. Bandín I, Dopazo CP. Host range, host specificity and hypothesized host shift events among viruses of lower vertebrates. Vet Res. 2011;42:67. 
9. Sun L, Tu J, Yi L, Chen W, Zhao L, Huang Y, et al. Pathogenicity of snakehead vesiculovirus in rice field eels (Monopterus albus). Microb Pathog. 2017;110:578-85

10. Gui JF, Zhu ZY. Molecular basis and genetic improvement of economically important traits in aquaculture animals. Chin Sci Bull. 2012;57:1751-60.

11. Zhang QY, Gui JF. Atlas of aquatic viruses and viral diseases. Beijing: Science Press; 2012

12. Zhang QY, Gui JF. Virus genomes and virus-host interactions in aquaculture animals. Sci China Life Sci. 2015;58:156-69.

13. Jancovich JK, Chinchar VG, Hyatt A, Miyazaki T, Williams T, Zhang QY. Family Iridoviridae. In: King AMQ, Lefkowitz E, Adams MJ, Carstens EB, editors. Virus taxonomy: ninth report of the international committee on taxonomy of viruses. SanDiego: Elsevier; 2011. p. 193-210.

14. Chinchar VG, Hick P, Ince IA, Jancovich JK, Marschang R, Qin Q, et al. ICTV virus taxonomy profile: Iridoviridae. J Gen Virol. 2017a;98:890-1.

15. Chinchar VG, Waltzek TB. Ranaviruses: not just for frogs. PLoS Pathog. 2014 10:e1003850.

16. Whittington RJ, Becker JA, Dennis MM. Iridovirus infections in finfish critical review with emphasis on ranaviruses. J Fish Dis. 2010;33:95-122.

17. George MR, John KR, Mansoor MM, Saravanakumar R, Sundar P, Pradeep V. Isolation and characterization of a ranavirus from koi, Cyprinus carpio L., experiencing mass mortalities in India. J Fish Dis. 2015;38:389-403.

18. Chinchar VG, Waltzek TB, Subramaniam K. Ranaviruses and other members of the family Iridoviridae: their place in the virosphere. Virology. 2017b; https://doi.org/10.1016/j.virol.2017.06.007.

19. Zhang QY, Xiao F, Li ZQ, Gui JF, Mao J, Chinchar VG. Characterization of an iridovirus from the cultured pig frog Rana grylio with lethal syndrome. Dis Aquat Org. 2001;48:27-36.

20. Chinchar VG. Ranaviruses (family Iridoviridae): emerging cold-blooded killers. Arch Virol. 2002;147:447-70.

21. Chinchar VG, Yu KH, Jancovich JK. The molecular biology of frog virus 3 and other iridoviruses infecting cold-blooded vertebrates. Viruses. 2011:3:1959-85.

22. Marschang RE, Becher P, Posthaus H, Wild P, Thiel HJ, Müller-Doblies U, et al. Isolation and characterization of an iridovirus from Hermann's tortoises (Testudo hermanni). Arch Virol. 1999;144:1909-22.

23. Huang Y, Huang X, Liu H, Gong J, Ouyang Z, Cui H, et al. Complete sequence determination of a novel reptile iridovirus isolated from softshelled turtle and evolutionary analysis of Iridoviridae. BMC Genomics. 2009;10:224

24. Jancovich JK, Bremont M, Touchman JW, Jacobs BL. Evidence for multiple recent host species shifts among the Ranaviruses (family Iridoviridae). J Virol. 2010;84:2636-47.

25. Abrams AJ, Cannatella DC, Hillis DM, Sawyer SL. Recent host-shifts in ranaviruses: signatures of positive selection in the viral genome. J Gen Virol. 2013;94:2082-93.

26. Schock DM, Bollinger TK, Chinchar VG, Jancovich JK, Collins JP. Experimental evidence that amphibian ranaviruses are multi-host pathogens. Copeia. 2008;1:133-43

27. Brenes R, Miller DL, Waltzek TB, Wilkes RP, Tucker JL, Chaney JC, et al. Susceptibility of fish and turtles to three ranaviruses isolated from different ectothermic vertebrate classes. J Aquat Anim Health. 2014;26:118-26.

28. Huang $X H$, Huang YH, Yuan XP, Zhang QY. Electron microscopic examination of the viromatrix of Rana grylio virus in a fish cell line. J Virol Methods. 2006;133:117-23.

29. Zhao Z, Ke F, Huang YH, Zhao JG, Gui JF, Zhang QY. Identification and characterization of a novel envelope protein in Rana grylio virus. J Gen Virol. 2008:89:1866-72

30. Lei XY, Ou T, Zhang QY. Rana grylio virus (RGV) $50 \mathrm{~L}$ is associated with viral matrix and exhibited two distribution patterns. PLoS One. 2012a;7:e43033.

31. Lei $X Y, O u T$, Zhu RL, Zhang QY. Sequencing and analysis of the complete genome of Rana grylio virus (RGV). Arch Virol. 2012b;157:1559-64.

32. Chen Z, Gui J, Gao X, Pei C, Hong Y, Zhang Q. Genome architecture changes and major gene variations of Andrias davidianus ranavirus (ADRV) Vet Res. 2013:44:101.

33. He LB, Gao XC, Ke F, Zhang QY. A conditional lethal mutation in Rana grylio virus ORF 53R resulted in a marked reduction in virion formation. Virus Res. 2013;177:194-200

34. He LB, Ke F, Wang J, Gao XC, Zhang QY. Rana grylio virus (RGV) envelope protein $2 \mathrm{~L}$ : subcellular localization and essential roles in virus infectivity revealed by conditional lethal mutant. J Gen Virol. 2014;95: 679-90.
35. Huang X, Fang J, Chen Z, Zhang Q. Rana grylio virus TK and DUT gene locus could be simultaneously used for foreign gene expression. Virus Res. 2016;214:33-8.

36. Zhang QY, Li ZQ, Gui JF. Studies on morphogenesis and cellular interactions of Rana grylio virus in an infected fish cell line. Aquaculture. 1999;175:185-97.

37. Gao KQ, Shubin NH. Earliest known crown-group salamanders. Nature. 2003; 422:424-8.

38. Yuan JD, Chen ZY, Huang X, Gao XC, Zhang QY. Establishment of three cell lines from Chinese giant salamander and their sensitivities to the wild-type and recombinant ranavirus. Vet Res. 2015;46:58.

39. Lei CK, Chen ZY, Zhang QY. Comparative susceptibility of three aquatic animal cell lines to two ranaviruses. J Fish China. 2016:40:1643-7. (In Chinese)

40. Geng Y, Wang KY, Zhou ZY, Li CW, Wang J, He M, et al. First report of a ranavirus associated with morbidity and mortality in farmed Chinese giant salamanders (Andrias davidianus). J Comp Pathol. 2011;145(1):95-102.

41. Li D, Huang Z, Song S, Xin Y, Mao D, Lv Q, et al. Integrated analysis of phenome, genome, and transcriptome of hybrid rice uncovered multiple heterosis-related loci for yield increase. Proc Natl Acad Sci U S A. 2016;113: E6026-35.

42. Breschi A, Gingeras TR, Guigó R. Comparative transcriptomics in human and mouse. Nat Rev Genet. 2017;18:425-40.

43. Tarifeño-Saldivia E, Lavergne A, Bernard A, Padamata K, Bergemann D, Voz $\mathrm{ML}$, et al. Transcriptome analysis of pancreatic cells across distant species highlights novel important regulator genes. BMC Biol. 2017;15:21.

44. Joseph U, Su YC, Vijaykrishna D, Smith GJ. The ecology and adaptive evolution of influenza a interspecies transmission. Influenza Other Respir Viruses. 2017;11:74-84.

45. Spicer BA, Conroy PJ, Law RHP, Voskoboinik I, Whisstock JC. Perforin - a key (shaped) weapon in the immunological arsenal. Semin Cell Dev Biol. 2017; https://doi.org/10.1016/j.semcdb.2017.07.033.

46. Peaper DR, Cresswell P. Regulation of MHC class I assembly and peptide binding. Annu Rev Cell Dev Biol. 2008:24:343-68.

47. Budida R, Stankov MV, Döhner K, Buch A, Panayotova-Dimitrova D, Tappe KA, et al. Herpes simplex virus 1 interferes with autophagy of murine dendritic cells and impairs their ability to stimulate $\mathrm{CD} 8^{+} \mathrm{T}$ lymphocytes. Eur J Immunol. 2017; https://doi.org/10.1002/eji.201646908.

48. Paull SH, Song S, McClure KM, Sackett LC, Kilpatrick AM, Johnson PT. From superspreaders to disease hotspots: linking transmission across hosts and space. Front Ecol Environ. 2012;10:75-82.

49. Gray MJ, Miller DL, Hoverman JT. Ecology and pathology of amphibian ranaviruses. Dis Aquat Org. 2009;87:243-66.

50. Hoverman JT, Gray MJ, Haislip NA, Miller DL. Phylogeny, life history, and ecology contribute to differences in amphibian susceptibility to ranaviruses. EcoHealth. 2011;8:301-19.

51. Bang-Jensen B, Holopainen R, Tapiovaara H, Ariel E. Susceptibility of pikeperch Sander lucioperca to a panel of ranavirus isolates. Aquaculture. 2011 313:24-30.

52. Kolev M, Le Friec G, Kemper C. Complement - tapping into new sites and effector systems. Nat Rev Immunol. 2014;14:811-20.

53. Agrawal P, Nawadkar R, Ojha H, Kumar J, Sahu A. Complement evasion strategies of viruses: an overview. Front Microbiol. 2017:8:1117.

54. Hamad OA, Bäck J, Nilsson PH, Nilsson B, Ekdahl KN. Platelets, complement, and contact activation: partners in inflammation and thrombosis. Adv Exp Med Biol. 2012;946:185-205.

55. Meri S. Complement activation in diseases presenting with thrombotic microangiopathy. Eur J Intern Med. 2013;24:496-502.

56. Cotter JD, Storfer A, Page RB, Beachy CK, Voss SR. Transcriptional response of Mexican axolotls to Ambystoma tigrinum virus (ATV) infection. BMC Genomics. 2008;9:493.

57. Haislip NA, Gray MJ, Hoverman JT, Miller DL. Development and disease: how susceptibility to an emerging pathogen changes through anuran development. PLoS One. 2011;6(7):e22307.

58. Zhu R, Chen ZY, Wang J, Yuan JD, Liao XY, Gui JF, et al. Thymus cDNA library survey uncovers novel features of immune molecules in Chinese giant salamander Andrias davidianus. Dev Comp Immunol. 2014:46:413-22.

59. Fan Y, Chang MX, Ma J, LaPatra SE, Hu YW, Huang L, et al. Transcriptomic analysis of the host response to an iridovirus infection in Chinese giant salamander. Andrias davidianus Vet Res. 2015;46:136

60. Price SJ, Garner TW, Balloux F, Ruis C, Paszkiewicz KH, Moore K, et al. A de novo assembly of the common frog (Rana temporaria) transcriptome and 
comparison of transcription following exposure to ranavirus and Batrachochytrium dendrobatidis. PLoS One. 2015;10:e0130500.

61. Burwitz BJ, Malouli D, Bimber BN, Reed JS, Ventura AB, Hancock MH, et al. Cross-species rhesus cytomegalovirus infection of Cynomolgus macaques. PLoS Pathog. 2016;12:e1006014.

62. Griffin $B D$, Verweij MC, Wiertz EJ. Herpesviruses and immunity: the art of evasion. Vet Microbiol. 2010;143:89-100.

63. Grayfer L, Andino F, Chen G, Chinchar VG, Robert J. Immune evasion strategies of ranaviruses and innate immune responses to these emerging pathogens. Viruses. 2012;4:1075-92.

64. Robert J, Edholm ES, Jazz S, Odalys TL, Francisco JA. Xenopus-FV3 hostpathogen interactions and immune evasion. Virology. 2017; https://doi.org/10.1016/j.virol.2017.06.005.

65. Grabherr MG, Haas BJ, Yassour M, Levin JZ, Thompson DA, Amit I, et al. Full-length transcriptome assembly from RNA-Seq data without a reference genome. Nat Biotechnol. 2011;29:644-52.

66. Li B, Dewey CN. RSEM: accurate transcript quantification from RNA-Seq data with or without a reference genome. BMC Bioinformatics. 2011;12:323.

67. Langmead B, Salzberg SL. Fast gapped-read alignment with bowtie 2 . Nat Methods. 2012;9:357-9.

68. Liao Y, Smyth GK, Shi W. FeatureCounts: an efficient general purpose program for assigning sequence reads to genomic features. Bioinformatics. 2014;30:923-30.

69. Robinson MD, McCarthy DJ, Smyth GK. edgeR: a Bioconductor package for differential expression analysis of digital gene expression data. Bioinformatics. 2010;26:139-40.

70. Chen H, Boutros PC. VennDiagram: a package for the generation of highlycustomizable Venn and Euler diagrams in R. BMC Bioinformatics. 2011;12:35.

71. Conesa A, Gotz S, Garcia-Gomez JM, Terol J, Talon M, Robles M. Blast2GO: a universal tool for annotation, visualization and analysis in functional genomics research. Bioinformatics. 2005;21:3674-6.

72. Kanehisa M, Araki M, Goto S, Hattori M, Hirakawa M, Itoh M, et al. KEGG for linking genomes to life and the environment. Nucleic Acids Res. 2008;36: D480-4.

73. Tang H, Wang X, Bowers JE, Ming R, Alam M, Paterson AH. Unraveling ancient hexaploidy through multiply-aligned angiosperm gene maps. Genome Res. 2008;18:1944-54.

74. Xie C, Mao X, Huang J, Ding Y, Wu J, Dong S, et al. KOBAS 2.0: a web server for annotation and identification of enriched pathways and diseases. Nucleic Acids Res. 2011;39:W316-22.

75. Lu J, Peatman E, Tang H, Lewis J, Liu Z. Profiling of gene duplication patterns of sequenced teleost genomes: evidence for rapid lineage-specific genome expansion mediated by recent tandem duplications. BMC Genomics. 2012;13:246.

76. Livak KJ, Schmittgen TD. Analysis of relative gene expression data using real-time quantitative $P C R$ and the $2^{-\Delta \Delta C T}$ method. Methods. 2001;25:402-8.

\section{Submit your next manuscript to BioMed Central and we will help you at every step:}

- We accept pre-submission inquiries

- Our selector tool helps you to find the most relevant journal

- We provide round the clock customer support

- Convenient online submission

- Thorough peer review

- Inclusion in PubMed and all major indexing services

- Maximum visibility for your research

Submit your manuscript at www.biomedcentral.com/submit

) Biomed Central 